\title{
Species or Genotypes? Reassessment of Four Recently Described Species of the Ceratocystis Wilt Pathogen, Ceratocystis fimbriata, on Mangifera indica
}

\author{
Leonardo S. S. Oliveira, Thomas C. Harrington, Maria A. Ferreira, Michelle B. Damacena, Abdullah M. Al-Sadi, \\ Issa H. S. Al-Mahmooli, and Acelino C. Alfenas
}

First, fourth, and seventh authors: Departamento de Fitopatologia, Universidade Federal de Viçosa, Viçosa, MG 36570-900, Brazil; second author: Department of Plant Pathology and Microbiology, Iowa State University, Ames 50011; third author: Departamento de Fitopatologia, Universidade Federal de Lavras, Lavras, MG 37200-000, Brazil; and fifth and sixth authors: Department of Crop Sciences, Sultan Qaboos University, P.O. Box 34, AlKhoud 123, Oman.

Accepted for publication 25 March 2015.

\begin{abstract}
Oliveira, L. S. S., Harrington, T. C., Ferreira, M. A., Damacena, M. B., Al-Sadi, A. M., Al-Mahmooli, I. H. S., and Alfenas, A. C. 2015. Species or genotypes? Reassessment of four recently described species of the Ceratocystis wilt pathogen, Ceratocystis fimbriata, on Mangifera indica. Phytopathology 105:1229-1244.

Ceratocystis wilt is among the most important diseases on mango (Mangifera indica) in Brazil, Oman, and Pakistan. The causal agent was originally identified in Brazil as Ceratocystis fimbriata, which is considered by some as a complex of many cryptic species, and four new species on mango trees were distinguished from $C$. fimbriata based on variation in internal transcribed spacer sequences. In the present study, phylogenetic analyses using DNA sequences of mating type genes, TEF-1 $\alpha$, and

a tester strain from sweet potato (Ipomoea batatas), on which the name $C$. fimbriata is based, and there was little morphological variation among the mango isolates. Microsatellite markers found substantial differentiation among mango isolates at the regional and population levels, but certain microsatellite genotypes were commonly found in multiple populations, suggesting that these genotypes had been disseminated in infected nursery stock. The most common microsatellite genotypes corresponded to the four recently named species (C. manginecans, $C$. acaciivora, $C$. mangicola, and C. mangivora), which are considered synonyms of $C$. fimbriata. This study points to the potential problems of naming new species based on introduced genotypes of a pathogen, the value of an understanding of natural variation within and among populations, and the importance of phenotype in delimiting species.
\end{abstract} $\beta$-tubulin failed to identify lineages corresponding to the four new species names. Further, mating experiments found that the mango isolates representing the new species were interfertile with each other and
Additional keywords: pathogen diversity, population biology, species concepts.
Sequences of DNA and population-based genetic markers have greatly aided in the delineation of fungal plant pathogens, but they do not always clearly distinguish between cryptic species and genetically isolated populations or introduced genotypes. Distinguishing fungal lineages as new species rather than populations often appears arbitrary without the study of phenotype. The problem of species delineation is particularly evident in the Ceratocystis fimbriata Ellis \& Halsted complex, especially in the soilborne Latin American Clade (LAC) of the complex, which is native to Eastern United States, Mexico, the Caribbean, Central America, and South America (Harrington et al. 2011). Recently, 14 new species have been described in the LAC as distinct from a widely distributed genotype in storage roots of Ipomoea batatas (sweet potato), on which the name C. fimbriata is based (Engelbrecht and Harrington 2005; van Wyk et al. 2007, 2009, 2010, 2011a, 2011b, 2012).

The new species in the LAC were mainly distinguished by differences in the internal transcribed spacer (ITS) region of rDNA and mostly using isolates from an introduced population or a limited number of collection sites (Harrington et al. 2014). Two of the new species in the LAC were based on specialization to native hosts as a distinguishing phenotypic character: C. platani Engelbr. \& T.C. Harrin. on Platanus occidentalis in Eastern United States and C. cacaofunesta Engelbr. \& T.C. Harrin. on Theobroma cacao from the Upper Amazon (Engelbrecht and Harrington 2005). Host

Corresponding author: T. C. Harrington; E-mail address: tcharrin@iastate.edu specialization to nonnative hosts is suggested by the basionyms of some of the new species, such as C. manginecans M. van Wyk, A. Adawi \& M.J. Wingf., C. mangivora M. van Wyk \& M.J. Wingf. and C. mangicola M. van Wyk \& M.J. Wingf. on Mangifera indica (mango), and C. acaciivora Tarigan \& M. van Wyk on Acacia spp. and mango (Tarigan et al. 2011; van Wyk et al. 2007, 2011a). However, host specialization and morphological distinctions have not been documented clearly, and mating studies have found that Brazilian isolates from mango are a single biological species and sexually compatible with a sweet potato strain of $C$. fimbriata (Ferreira et al. 2010).

Mango is native to southern and southeastern Asia (Kostermans and Bompard 1993), but the first report of Ceratocystis wilt on mango trees occurred in Brazil in the Northeastern state of Pernambuco (Carvalho 1938). The causal agent was later identified as $C$. fimbriata and confirmed in São Paulo, Brazil (Viégas 1960), where it remains a serious disease in commercial mango plantations. Ceratocystis wilt on mango was later confirmed in the states of Bahia (Batista et al. 2008), Rio de Janeiro (Baker et al. 2003; Ferreira et al. 2010; Silveira et al. 2006), and Distrito Federal (Harrington et al. 2014). The disease on mango was observed for the first time outside Brazil in Pakistan (Fateh et al. 2006) and the Sultanate of Oman (Al Adawi et al. 2006), where it causes serious losses to mango and also attacks an important forest species, Dalbergia sissoo in Pakistan (Poussio et al. 2010). An isolate from Punica granatum (pomegranate) in India (Somasekhara 1999) appears to be the same as the mango pathogen in Pakistan and Oman, which is believed to be an introduced strain from South America (Harrington et al. 2014).

The mango pathogen in Oman and Pakistan was named C. manginecans (van Wyk et al. 2007) based on a unique ITS 
sequence, referred to by Harrington et al. (2014) as ITS7b. Later, a second ITS sequence (designated ITS6) was found in Oman, and this was described as a second species, $C$. acaciivora, because the same ITS sequence also was found in isolates from Acacia spp. in Indonesia (Tarigan et al. 2011). The ITS sequences of the LAC can vary widely, even within populations (Harrington et al. 2011, 2014), and the presence of both ITS7b and ITS6 was found in single-ascospore isolates of $C$. fimbriata from Oman and Pakistan (Harrington et al. 2014, Naidoo et al. 2013), and ITS6 and other ITS sequences were recovered from a pomegranate isolate in India and a mango isolate in western Rio de Janeiro (Harrington et al. 2014). Two other new species were named from mango isolates in São Paulo as $C$. mangicola and C. mangivora based on ITS sequences (van Wyk et al. 2011a), but these species names may merely represent genotypes of $C$. fimbriata that have been distributed in nursery stock (Harrington et al. 2014).

The primary aim of this study was to test the hypothesis that there are cryptic species among isolates of the C. fimbriata complex on mango in Brazil, Oman, and Pakistan. Elements of three concepts for species recognition were applied. For genealogical concordance phylogenetic species recognition, species may be delimited by phylogenetic analyses alone, although adequate sampling of populations is necessary (Taylor et al. 2000). The traditional phylogenetic species concept (Harrington and Rizzo 1999) relies on a unique phenotype to designate a phylogenetic lineage as a species, considering phenotype in a broad sense, including morphology, physiology, and ecology. This concept defines a species as "...the smallest aggregation of populations with a common lineage that share unique, diagnosable characters." A third alternative is the traditional biological species concept, in which prezygotic or postzygotic barriers delimit species (Harrington and Rizzo 1999).

In an attempt to adequately sample both natural and humanmediated populations, isolates were obtained from dead and dying mango trees wherever the disease was known (Oman, Pakistan, and Brazil) and in all other states in Brazil where there had been reports of mango mortality. Sequences of the ITS region were used to place the isolates among the previously described species and identify new ITS genotypes (Harrington et al. 2014). Phylogenetic analyses were conducted with DNA sequences from four gene-coding regions to identify phylogenetic lineages, and representative isolates from different regions were examined for morphological distinctions. Interfertility tests were conducted to identify possible biological species. Microsatellite markers were utilized to determine the genetic structure of the populations and to see if the recently described species were common genotypes or clones found at multiple locations, implying that they had been moved in infected nursery stock (Harrington et al. 2014).

\section{MATERIALS AND METHODS}

Collection of isolates. Isolates were collected from diseased mango trees in plantations, small farms, gardens, and along streets in small cities across Brazil, Oman, and Pakistan. We consulted local agronomists, plant pathologists, and local newspapers for reports of mango mortality and visited all reports of the disease in Brazil. In addition to the five states in Brazil where Ceratocystis wilt on mango had been previously reported (Fig. 1), the disease was found in Minas Gerais, Paraíba, Alagoas, and Ceará. Mango trees in Pará, Piauí, Sergipe, and Espírito Santo were also examined, but no mango plant with Ceratocystis wilt was found.

Trees showing symptoms of branch death, wilting foliage, bark discoloration, or sap exudation were examined by chopping into the woody xylem at the base of the tree (most infections occur through the root system) or further up the stems for the characteristic xylem discoloration, pieces of which were brought back to the laboratory for isolation attempts (Ferreira et al. 2010). For the new isolates, a single ascospore strain was derived from the original field isolate by dispersing an ascospore mass in a light oil and spreading the spore suspension over the plate; individual germlings were subcultured to fresh plates (Harrington and McNew 1997). Aside from 28 mango isolates from Brazil and Pakistan studied previously (Ferreira et al. 2010; Harrington et al. 2011, 2014), 186 new isolates were obtained from mango trees in Brazil and Oman in 2011 to 2013. The fungus can potentially move from a single infection court

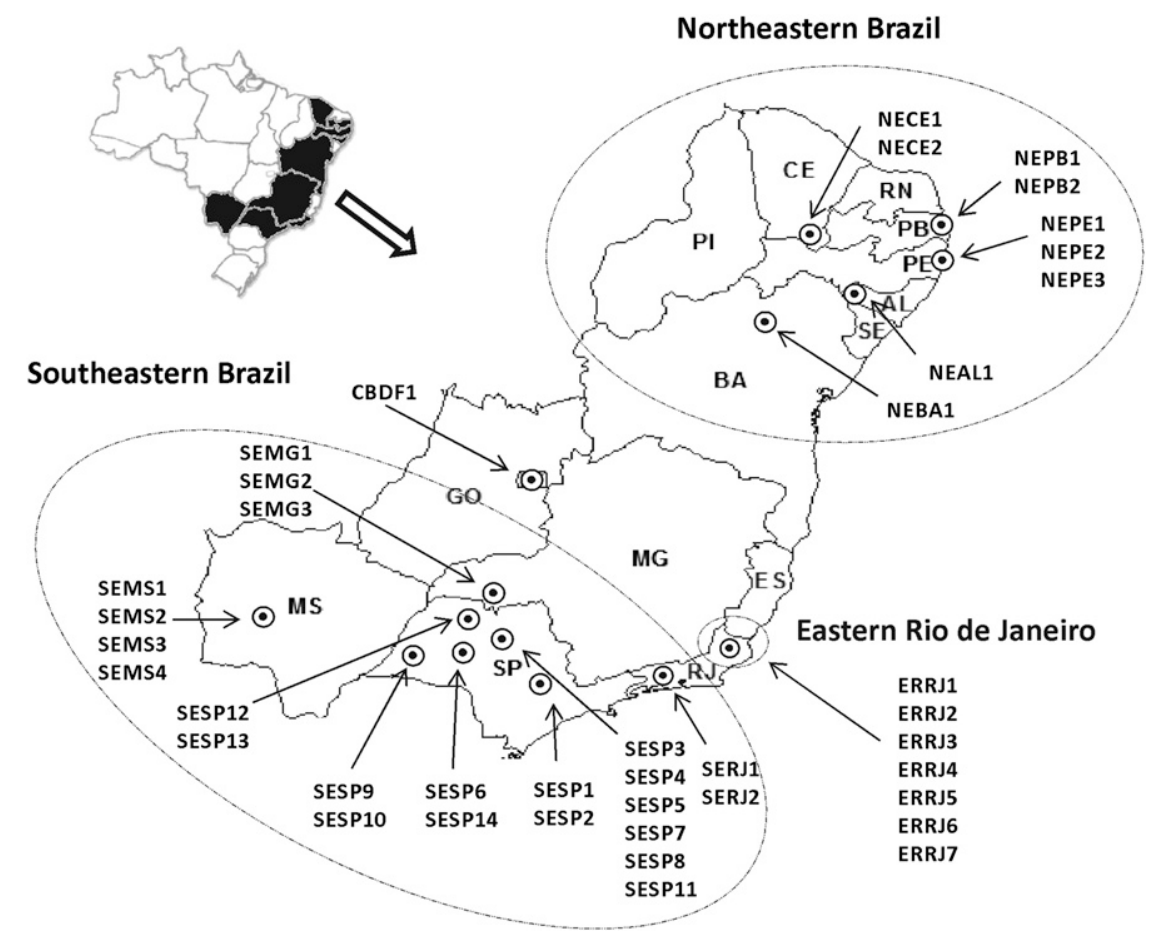

Fig. 1. Forty sites in Brazil where Ceratocystis fimbriata was collected from Mangifera indica (mango). The first two letters of each location indicate the geographic region ( $\mathrm{SE}=$ Southeastern Brazil; NE = Northeastern Brazil; ER = Eastern Rio de Janeiro; and CB = Central Brazil) and the next two letters indicate the state of origin (SP = São Paulo; RJ = Rio de Janeiro; MS = Mato Grosso do Sul; MG = Minas Gerais; DF = Distríto Federal; $\mathrm{BA}=\mathrm{Bahia} ; \mathrm{PE}=\mathrm{Pernambuco}$; PB = Paraíba; $\mathrm{AL}=$ Alagoas; and $\mathrm{CE}=$ Ceará) . 
throughout a tree, so only one isolate per tree was used in genetic analyses.

Each population in Brazil consisted of at least four isolates from a small city, from a group of small farms in and around a small city, or from a single large plantation. All but a single isolate from Central Brazil (CB) were considered to be from one of three geographic regions: Southeastern Brazil (SE), Northeastern Brazil (NE), and Eastern Rio de Janeiro (ER). Ceratocystis wilt on mango is well known and has been well studied in commercial plantations in Southeastern Brazil, primarily in the state of São Paulo, where the pathogen has been associated with nursery stock. Near Limeira, São Paulo, where much of the nursery industry is located, 11 isolates (SESP1) were obtained from a row of diseased mango trees in an abandoned nursery. Other collections in the Southeast were from small cities or farms, but four populations were sampled from four large plantations: SESP7, SEMG1, SESP5, and SESP11. Isolates from the western part of Rio de Janeiro are genetically similar to mango isolates from São Paulo (Ferreira et al. 2010; Harrington et al. 2014), and the earlier studied isolates were included as a Southeastern population (SERJ2), as were additional isolates from the city of Paraíba do Sul (SERJ1). Ceratocystis wilt on mango was found in various small cities in the Northeast, but we were unable to locate diseased plantations, even in Pernambuco, the largest mango producing state in Brazil. Earlier studies demonstrated that Eastern Rio de Janeiro isolates were genetically distinct from other mango isolates (Baker et al. 2003; Ferreira et al. 2010; Harrington et al. 2014; Silveira et al. 2006). The earlier isolates were not included, but the newly collected isolates from small cities and one plantation (ERRJ3) in Eastern Rio de Janeiro were confirmed to be genetically similar to the earlier isolates and distinct from all other mango populations. Thus, the Eastern Rio de Janeiro isolates were treated as a third regional group.

In Oman, all the isolates were collected from small farms in the Al-Batinah, Muscat, and Musandam regions in the coastal plains of Northastern Oman, near the cities of Barka, Almosna'h, Quriyat, Al-Seeb, Swaiq, Sohar, Shinas, Saham, and Madha. The Oman isolates represented a single population, though the collection sites were up to $305 \mathrm{~km}$ apart. The Pakistani isolates were collected in a previous study (Harrington et al. 2014) from mango trees in five regions over a distance of about 2,000 km. Isolates from Pakistan were also considered to comprise a single population, and the entire Oman/Pakistan collection was considered to be from a single region.

Referenced isolates. Representatives of previously described species and populations on mango used for phylogenetic analyses included isolate CBS 600.70 (=C994), used to describe $C$. mangivora; CBS 114721 (=C1688), the ex-holotype of $C$. mangicola; CBS 115175 $(=\mathrm{C} 1558)$ as a representative of the Eastern Rio de Janeiro population on mango; CBS 135866 (=C2757) and CBS 135868 (=C2759) from Pakistan; and CBS 135988 (=C2785) and CBS 135867 (=C2787) from Oman. Other reference strains of $C$. fimbriata included CBS 115174 (=C1442) from Eucalyptus in Bahia; CBS 115166 (=C1782) from Ficus carica in São Paulo; CBS 115171 (=C1905) and CBS 114713 (=C1865) from Colocasia esculenta in São Paulo; CBS 115173 (=C918) from Gmelina arborea in Pará; and ICMP 8579 (=C1476) from Ipomoea batatas in Papua New Guinea. Other isolates included CBS 153.62 (=C1004), representing C. cacaofunesta ; CBS 135861 (=C1543), representing C. colombiana; CBS 115162 (=C1317), representing C. platani; and CBS 135862 (=C1963), representing the outgroup taxon C. variospora.

ITS barcoding. Amplification and direct sequencing of the ITS rDNA region utilized primers ITS1F and ITS4 following conditions described in Harrington et al. (2011). All sequencing was conducted by the Iowa State University DNA Facility. One of the new, singleascospored isolates from Oman appeared to have a mixed ITS polymerase chain reaction (PCR) product that could not be clearly determined using direct sequencing, so the PCR product was cloned into the pGEM-T Easy vector (Promega Corporation, Madison, WI). Plasmids were extracted using Ilustra plasmidPrep Mini Spin Kit (GE Healthcare Life Sciences, Buckinghamshire, UK), and the cloned fragments were sequenced using vector primers T7-2 and SP6.

The ITS sequences of the 214 mango isolates were compared with those reported earlier for the LAC (Harrington et al. 2011, 2014). Relationships among the mango ITS sequences were examined using genetic distance (Nei's) matrices, unweighted pair group method, arithmetic mean dendrogram (UPGMA) trees, and 1,000 bootstrap replications generated with PAUP 4.0b10 (Swofford 2002).

$\boldsymbol{\beta}$-tubulin gene sequences. Gene sequences of $\beta$-tubulin were obtained using PCR (600-bp fragment) followed by direct DNA sequencing with primers BT1- $\alpha\left(5^{\prime}\right.$-TTCCCCCGTCTCCACTTCTT CATG- $\left.3^{\prime}\right)$ and BT1- $\beta$ ( $5^{\prime}$-GACGAGATCGTTCATGTTGAACTC-3') (Glass and Donaldson 1995). The thermocycler settings for amplifying the $\beta$-tubulin region included initial denaturation at $94^{\circ} \mathrm{C}$ for $4 \mathrm{~min}$, with 30 cycles of $94^{\circ} \mathrm{C}$ for $50 \mathrm{~s}, 55^{\circ} \mathrm{C}$ for $50 \mathrm{~s}, 72^{\circ} \mathrm{C}$ for $50 \mathrm{~s}$, and a final extension at $72^{\circ} \mathrm{C}$ for $10 \mathrm{~min}$.

TEF-1 $\alpha$ gene sequences. The primers EFCF1 (5'-AGTGCG GTGGTATCGACAAG-3'), EFCF2 (5'-TGCTCAACGGGTCTG GCCAT-3'), EFCF3 (5'-ATGGCCAGACCCGTGAGCA-3') and EFCF6 (5'-CATGTCACGGACGGCGAAAC-3') were developed for amplification and sequencing in an earlier study (Harrington 2009). The primers EFCF1 and EFCF6 were used for amplification and sequencing, and two additional primers (EFCF2 and EFCF3) were used to sequence about a 1,600-bp region that included portions of three exons and two introns. Thermocycler settings for amplifying the TEF- $1 \alpha$ region included: initial denaturation at $85^{\circ} \mathrm{C}$ for $2 \mathrm{~min}$ followed by $94^{\circ} \mathrm{C}$ for $1 \mathrm{~min}$ and $35 \mathrm{~s}$, with 36 cycles of $60^{\circ} \mathrm{C}$ for $1 \mathrm{~min}$, $72^{\circ} \mathrm{C}$ for $1 \mathrm{~min}$ and $30 \mathrm{~s}$, and $94^{\circ} \mathrm{C}$ for $35 \mathrm{~s}$, followed by final extension of $72^{\circ} \mathrm{C}$ for $15 \mathrm{~min}$. The fragments were purified and sequenced as described above.

Mating type gene sequences. Most field isolates of C. fimbriata are self-fertile and have genes associated with both the MAT2 and MAT1 mating types in the mating type locus. However, during unidirectional mating-type switching, the gene associated with the MAT2 phenotype (MAT1-2-1) is deleted, and progeny that have inherited nuclei with the deletion behave as MAT1 and are self-sterile (Harrington and McNew 1997; Wilken et al. 2014; Witthuhn et al. 2000). Portions of the mating type locus associated with the MAT1 phenotype (MAT1-1-2) and MAT2 phenotype (MAT1-2-1) of all self-fertile isolates were amplified and sequenced using the primers and protocols of Harrington et al. (2014). Primers CFMAT1-F (5'-CAGCCTCGATTGAKGGTATGA-3') and CFMAT1-R (5'-GGC ATTTTTACGCTGGTTAG-3') were used to amplify and sequence about $1,000 \mathrm{bp}$ of the MAT1-1-2 region. The primers $\times 9978 \mathrm{a}\left(5^{\prime}-\right.$ GCTAACCTTCACGCCAATTTTGCC- $\left.3^{\prime}\right)$ and CFM2-1F (5'-GTTA CAAGTGTTCCCAAAAG-3') were used to amplify and sequence about 1,150 bp that included most of the MAT1-2-1 gene. The thermocycler settings for amplifying both MAT1-1-2 and MAT1-2-1 regions included: initial denaturation at $94^{\circ} \mathrm{C}$ for $2 \mathrm{~min}$, with 36 cycles of $94^{\circ} \mathrm{C}$ for $1 \mathrm{~min}, 58^{\circ} \mathrm{C}$ for $1 \mathrm{~min}, 72^{\circ} \mathrm{C}$ for $2 \mathrm{~min}$, and a final extension of at $72^{\circ} \mathrm{C}$ for $10 \mathrm{~min}$. The fragments were purified and sequenced with the PCR primers as described above.

Phylogenetic analyses. Datasets for each of the four loci (MAT1, MAT2, TEF-1 $\alpha$, and $\beta$-tubulin) were separately aligned in MAFFT Online version v. 7.0 (Katoh and Toh 2010) using the FFT-NS-i (Slow; iterative refinement method) alignment strategy with the 200PAM/K=2 scoring matrix and a gap opening penalty of 1.53 with an offset value of 0.0 . Aligned sequences were then manually corrected when necessary using MEGA v. 5 (Tamura et al. 2011). Sequences of the four gene regions were analyzed separately and then a combined dataset was submitted to a partition homogeneity test (PHT) using PAUP 4.0b10 (Swofford 2002) in order to determine whether the datasets could be combined. For maximum parsimony analysis (PAUP 4.0b10), gaps were treated as a fifth base, all characters had equal weight, and the heuristic searches used simple stepwise addition and tree-bisection-reconnection. Bootstrap values were calculated using 1,000 replications. Phylogenetic trees were viewed and edited in Fig. Tree 1.3.1 (http://tree.bio.ed.ac.uk/software). 
Bayesian analyses were conducted using the Markov chain Monte Carlo algorithm implemented in Mr. Bayes v3.2.1 (Ronquist and Huelsenbeck 2003), and the best model of nucleotide substitution for each gene was selected according to Akaike information criterion using MrModeltest v. 2.3 (Nylander 2004). Bayesian inference was conducted with two sets of four chains (one cold and three heated) from a random tree with 10 million generations, and $25 \%$ of the first trees were discarded.

Mating experiments. Sexual compatibility (interfertility) was determined following the protocols used in other studies of the C. fimbriata complex (Engelbrecht and Harrington 2005; Ferreira et al. 2010; Johnson et al. 2005). Representative mango isolates from each region were selected as male and female testers in mating experiments. Also, isolates from Eucalyptus spp., Ficus carica, Colocasia esculenta, Gmelina arborea, and Ipomoea batatas, and one representative isolate of $C$. cacaofunesta and one of $C$. platani were selected as female testers in order to compare their interfertility with the mango isolates (Table 1).

C. fimbriata and many other species in the genus are homothallic through unidirectional mating type switching (Harrington and McNew 1997; Witthuhn et al. 2000). Most field isolates are selffertile and have the mating type genes that confer both mating types. In pairings, these field isolates are MAT2 in phenotype and can either cross with MAT1 strains or can self after deletion of the MAT1-2-1 gene (Wilken et al. 2014; Witthuhn et al. 2000), which changes the phenotype from MAT2 to MAT1. Both MAT2 (selffertile) and MAT1 (self-sterile due to deletion of the MAT1-2-1 gene) progeny are recovered from selfings of MAT2 strains (Harrington and McNew 1997; Witthuhn et al. 2000). Because MAT2 strains are generally self-fertile, mating experiments require selection of self-sterile MAT2 (male-only) testers that have lost femaleness (protoperithecia). Otherwise it is difficult to distinguish perithecia due to a cross from perithecia due to a selfing of the MAT2 tester.

The MAT2 testers were obtained by subculturing self-sterile mutants that formed spontaneously and appeared as sectors in colonies of otherwise self-fertile isolates. These MAT2 sectors lacked protoperithecia and thus did not form perithecia through selfing. To confirm that these mutants still were capable of behaving as MAT2 in a cross, genomic DNA of each MAT2, self-sterile sector was extracted, and PCR was performed to amplify a portion of the MAT12-1 gene using the primers CFM2-1F and $\times 9978$ a. The selected female
MAT1 testers were self-sterile, single ascospore strains recovered from self-fertile isolates and generally formed protoperithecia, thus indicating that they could serve as good female testers.

The MAT1 testers (female recipients) were grown on MYEA for 10 days at room temperature (approximately $23^{\circ} \mathrm{C}$ ) and then spermatized by MAT2 testers. The conidial suspensions of MAT2 testers were prepared by flooding a 10-day-old MYEA plate with $10 \mathrm{ml}$ of sterilized deionized water, scraping the mycelium with a sterile spatula. Then, $1 \mathrm{ml}$ of inoculum was dispersed over the MAT1 colony. The colonies were observed for 3 to 4 weeks for the presence of perithecia and ascospore masses. Ascospore masses from one or more perithecia of a cross were streaked onto fresh MYEA to observe whether the ascospores were viable and if the progeny had a uniform mycelial morphology, indicating an induced selfing had occurred, or if progeny showed the mycelial phenotypes of the two parents, indicating a successful cross. The experiment was repeated twice. The two strains were considered interfertile if they crossed in at least one of the two experiments. In the first experiment, ascospore masses were examined microscopically $(\times 400)$ to see if there were abundant, normal-appearing ascospores, indicating a good cross, or if there were no ascospores or only a few misshapen ascospores, which is typical of an interspecific cross or hybrid (Ferreira et al. 2010; Harrington and McNew 1998; Johnson et al. 2005).

Morphology. Representative mango isolates from the different regions were selected for morphological comparisons. These selffertile isolates were grown on MYEA for about 10 days at room temperature (approximately $23^{\circ} \mathrm{C}$ ). Measurements of endoconidia and endoconidiophores were made after 4 to 7 days growth, while perithecia and ascospores were measured after 7 to 10 days. Aleurioconidia were measured from cultures that had grown 7 to 20 days. Material from the cultures was mounted in lactophenol cotton blue and observed with Nomarsky interference microscopy. Size ranges were based on at least 10 observations, but some structures were rare or hard to locate in a few isolates, and fewer observations were made. Colony pigmentation was compared with the color chart of Rayner (1970).

Microsatellite markers. Variation in simple sequence repeats was used to study population structure and to identify widespread genotypes (genets) of $C$. fimbriata that may have been spread through human activity. We analyzed 14 microsatellite markers developed from an isolate of $C$. cacaofunesta (Steimel et al. 2004) and recently mapped onto the $C$. fimbriata genome (Simpson et al. 2013). The markers had been used in previous population studies on

TABLE 1. Interfertility (I), interspecific hybrid (H) interactions, and no interaction (-) between MAT2, male-only strains of Ceratocystis fimbriata from Mangifera indica (mango) with MAT1, female strains of $C$. fimbriata, C. platani, and C. cacaofunesta

\begin{tabular}{|c|c|c|c|c|c|c|c|c|}
\hline \multirow[b]{2}{*}{ Species } & \multirow[b]{2}{*}{ Host } & \multirow[b]{2}{*}{ MAT1, female } & \multicolumn{6}{|c|}{ MAT2, male ${ }^{a}$} \\
\hline & & & SESP5-1 sec ${ }^{b}$ & SEMS2-11 $\mathrm{sec}^{\mathrm{c}}$ & NECE2-1sec & OMAN1-8sec & ERRJ4-2sec & ERRJ1-10sec \\
\hline \multirow[t]{11}{*}{ C. fimbriata } & Mangifera & SESP5-1ss ${ }^{b}$ & $\mathrm{I}^{\mathrm{e}}$ & $-f^{f}$ & - & I & - & - \\
\hline & & SEMS2-11ss ${ }^{\mathrm{c}}$ & I & I & I & I & I & I \\
\hline & & NEBA1-10ss & I & - & I & I & I & I \\
\hline & & OMAN5-7ss ${ }^{\mathrm{d}}$ & I & I & I & I & I & I \\
\hline & & ERRJ4-2ss & - & I & I & I & I & I \\
\hline & & ERRJ2-2ss & I & - & I & I & I & I \\
\hline & Ficus & C1783ss & - & - & I & I & I & I \\
\hline & Gmelina & C918ss & - & - & I & I & - & - \\
\hline & Eucalyptus & C1347ss & I & I & I & I & I & I \\
\hline & Colocasia & C1926ss & I & - & I & I & I & I \\
\hline & Ipomoea & C1418ss & I & I & I & I & $\mathrm{I}$ & I \\
\hline C. cacaofunesta & Theobroma & $\mathrm{C} 1587 \mathrm{ss}$ & $\mathrm{H}^{\mathrm{g}}$ & $\mathrm{H}$ & $\mathrm{H}$ & $\mathrm{H}$ & $\mathrm{H}$ & $\mathrm{H}$ \\
\hline C. platani & Plantanus & C1317ss & $\mathrm{H}$ & $\mathrm{H}$ & $\mathrm{H}$ & $\mathrm{H}$ & $\mathrm{H}$ & $\mathrm{H}$ \\
\hline
\end{tabular}

${ }^{\text {a }} \sec =$ strains from MAT2, self-sterile sectors recovered from self-fertile isolates; ss = MAT1, female-competent isolates with protoperithecia.

b Isolate representing the previously named species $C$. mangicola (van Wyk et al. 2011a).

c Isolate representing the previously named species $C$. mangivora (van Wyk et al. 2011a)

d Isolate representing the previously named species C. manginecans (van Wyk et al. 2007).

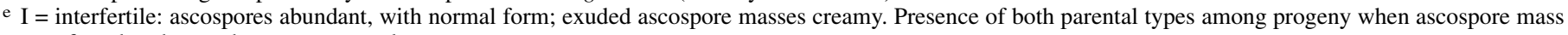
transferred and spread across a new plate.

f $-=$ no perithecia and ascospores produced.

g $\mathrm{H}=$ hybrid: much cellular debris and few misshapen ascospores inside perithecium; exuded ascospore masses, when present, watery in appearance. 
C. cacaofunesta (Engelbrecht et al. 2007), C. platani (Engelbrecht et al. 2004; Ocasio-Morales et al. 2007), C. pirilliforms (Nkuekam et al. 2009), and C. fimbriata (Ferreira et al. 2010, 2011; Harrington et al. 2015; van Wyk et al. 2006). Of the 16 markers used in earlier studies, two (CAT3K and CAT9x) were not utilized because their alleles (band sizes) could not be consistently resolved with some mango isolates. One primer of each pair was fluorescently labeled, and PCR amplifications were performed using a 96-well thermal cycler (PTC100 MJ Research Inc., Watertown, MA) as described in Ferreira et al. (2010). Band sizes of the products were determined using a fourcapillary ABI Prism 3100-Avant Genetic Analyzer (Applied Biosystems Inc., Foster City, CA) and ABI Peak Scanner v1.0 Analysis Software (Life Technologies). Each product length (within $1 \mathrm{bp}$ ) was considered to be a different allele.

Microsatellite analyses. Genetic variation of each mango population was compared with each other and representative C. fimbriata populations on Colocasia and Eucalyptus in Brazil using the microsatellite data (Ferreira et al. 2010). Besides the simple calculation of genotypic diversity (D, number of genotypes found in the population divided by the number of isolates sampled), multilocus genotypic diversity was estimated with the Stoddart and Taylor's $G$ index (Stoddart and Taylor 1988). The maximum value of $G$ is limited by the number of isolates sampled; therefore, $G$ was scaled by the expected number of genotypes for the smallest sample size being compared (Grünwald et al. 2003). For comparisons among individual populations, the expected number of genotypes in a sample of four isolates (minimum value $=1.0$ and maximum value $=4.0$ ) was estimated based on rarefaction curves using the $R$ package (version 2.9.1; R Development Core Team, Vienna). For comparisons among different regions or host groups, the maximum value of $G$ was 16 .

Partition of total variance using analysis of molecular variance (AMOVA) on Euclidean distances was performed using ARLEQUIN 2.0 (Excoffier et al. 2005) in order to determine variation among regions, among populations, and within populations. Nei's gene diversity of microsatellite loci for each population, the matrixes of Nei's genetic distance between populations, and a UPGMA dendrogram were constructed using PopGen 1.32 (Yeh and Boyle 1997). Bootstrap values for branches of the population trees were calculated from 100 replicates using SEQBOOT, GENDIST, NEIGHBOR, and CONSENSE in PHYLIP version 3.6 (Felsenstein 1993).

Each unique combination of the alleles among the 14 microsatellite loci was considered a microsatellite genotype. Relationships among the mango genotypes were examined using genetic distance (Nei's) matrices, UPGMA trees, and 1,000 bootstrap replications generated with PAUP 4.0b10 (Swofford 2002).

\section{RESULTS}

An exhaustive search for Ceratocystis wilt on mango in Brazil found that the disease was more widespread than expected, particularly on garden and street trees in the Northeast (Fig. 1). The combined sample of 214 mango isolates from 214 trees included 161 new isolates from Brazil, 25 new isolates from Oman, as well as 15 isolates from Brazil and 13 isolates from Pakistan that had been studied previously (Harrington et al. 2014).

ITS barcoding. The PCR product for all but one of the 186 new mango isolates could be directly sequenced for the ITS region. One Omani isolate apparently had a mixture of sequences among the tandem repeats of rDNA, as was earlier found in some mango isolates from Oman and Rio de Janeiro (Harrington et al. 2014). Nine cloned fragments from the ITS PCR product from this new Omani isolate yielded three clones with the ITS7b sequence and six clones with the ITS6 sequence (ITS genotype nomenclature of Harrington et al. 2014).

There was substantial variation among the mango isolates in ITS rDNA sequences, mostly due to variation in insertions/deletions (indels). Twenty-two unique ITS sequences were found among the 214 mango isolates, including 10 previously characterized ITS genotypes (Harrington et al. 2014). New ITS genotypes were designated by a unique letter suffix and compared with the other mango ITS genotypes using UPGMA analysis (Fig. 2). There was generally little relationship between geographic source of the isolates and relatedness of ITS sequences. However, the ITS7b genotype, described as C. manginecans (van Wyk et al. 2007), was only found in Oman and Pakistan (Fig. 2).

The three common ITS genotypes that were found at the most locations in Brazil corresponded with the sequences of three of the four recently named species (Tarigan et al. 2011; van Wyk et al. 2007, 2011a). The ITS6 genotype, described as $C$. acaciivora, was found on mango in 13 locations in Southeastern Brazil, as well as in most of the Oman and Pakistan locations (Fig. 2). The ITS14 genotype, named C. mangicola, was found at seven sites in Southeastern Brazil. The ITS10 genotype, named C. mangivora, was found at six collection sites in Southeastern Brazil and two collection sites in Northeastern Brazil.

$\boldsymbol{\beta}$-tubulin sequences. Fifty-four geographically representative mango isolates were sequenced for $\beta$-tubulin. Among the 564 aligned characters, seven different $\beta$-tubulin genotypes, mostly differing from each other at only one or two base positions, were identified. Five sequences were identified in Southeastern Brazil, and three of those sequences were also identified in Northeastern Brazil (GenBank KR002838-43). The isolates from Eastern Rio de Janeiro were uniform and unique for $\beta$-tubulin (GenBank KR002844).

Sequences (about $550 \mathrm{bp}$ ) of the $\beta$-tubulin region (EF433313, EF433308, EF433310, EU588643, EU588636, FJ200272, and FJ200280) from isolates that were used in the description of the four recently named species (Tarigan et al. 2011; van Wyk et al. 2007, 2011a) and those of another 23 isolates from other hosts representing the diversity of the LAC were included in phylogenetic analyses, with $C$. variospora as the outgroup taxon. For maximum parsimony (MP) analysis, 514 characters were constant, 35 were parsimonyuninformative, 15 were parsimony-informative, and there were 204 trees of 55 steps (Fig. 3), with a homoplasy index $(\mathrm{HI})=0.0323$, consistency index $(\mathrm{CI})=0.9677$, rescaled consistency index $(\mathrm{RC})=$ 0.9558 , and retention index $(\mathrm{RI})=0.9877$. The evolution model GTR + $\mathrm{G}$ for $\beta$-tubulin region was selected and incorporated into the Bayesian analysis.

None of the branches with sequences of mango isolates had both high bootstrap and posterior probability support (Fig. 3). Most of the mango isolates had one of two sequences, which differed solely in the number of CT repeats in the intron region. The sequence of the ex-types of C. mangicola and C. mangivora was identical to that of most of the mango isolates from Southeastern Brazil, and this sequence had one less CT repeat than the sequence from the ex-types of $C$. acaciivora and C. manginecans (Fig. 3). The latter sequence was found in isolates from mango, Eucalyptus, Acacia, and Gmelina from Southeastern and Northeastern Brazil, as well as in isolates from Oman, Pakistan, India, Indonesia, and South Africa (Fig. 3).

TEF-1 $\alpha$ sequences. The 54 representative mango isolates also were sequenced for TEF- $1 \alpha$ and compared with those of another 19 isolates from other hosts representing the diversity of the LAC, with C. variospora as the outgroup taxon. This dataset included 1,377 characters that were constant, 54 that were parsimony-uninformative, and 15 that were parsimony-informative. There were six most parsimonious trees of 74 steps (Fig. 4), with a $\mathrm{HI}=0.0412, \mathrm{CI}=$ $0.9588, \mathrm{RC}=0.9090$, and $\mathrm{RI}=0.9481$. Evolution model $\mathrm{HKY}+\mathrm{I}+\mathrm{G}$ was selected and incorporated into the Bayesian analysis. None of the isolates with ITS sequences matching the previously described species formed a monophyletic group in the TEF-1 $\alpha$ tree (Fig. 4). Isolates from Pakistan, Oman and India had the same TEF-1 $\alpha$ sequence as an isolate from Gmelina arborea in Pará, Brazil. The sequences of isolates representing $C$. mangicola (including the extype isolate $\mathrm{C} 1688$ ) and $C$. acaciivora were found scattered among the different branches. The TEF- $1 \alpha$ sequence of isolates representing C. mangivora (including C994 from the original description) was identical to that of most of the isolates of $C$. fimbriata from Brazil and a U.S. isolate from Ipomoea (Fig. 4). 
Partial TEF-1 $\alpha$ sequences (664 bp, matching the $5^{\prime}$ end of our sequences) for 16 isolates from the original descriptions of the four recently named species (Tarigan et al. 2011; van Wyk et al. 2007, 2011a) were available in GenBank (EF433316-23, EU588646-7, EU588653-4, FJ200285-6, and FJ200293-4). The partial overlap of these sequences with our longer TEF- $1 \alpha$ sequences was used to confirm that our sequences adequately represented the four respective species. Partial sequences (FJ200285, FJ200286, and EF433316, respectively) from isolates CMW28913, CMW28914, and CBS 114721 (=CMW14797 = C1688) representing $C$. mangicola matched the TEF- $1 \alpha$ sequence of some of our mango isolates from São Paulo (e.g., C1688, SESP5-9, SESP11-7, and SESP1-6 in Figure 4). Nine of the partial sequences representing C. mangivora, C. manginecans, and C. acaciivora from Brazil, Pakistan, and Indonesia (Tarigan et al. 2011; van Wyk et al. 2007, 2011a) were identical and matched the common TEF-1 $\alpha$ sequence found in isolates from mango, Eucalyptus, and Acacia spp. in Northeastern and Southeastern Brazil, the Ipomoea isolate, and representatives of C. cacaofunesta (Fig. 4).

Mating type sequences. An alignment of 1,033 characters had nine characters varying and four MAT1-1-2 genotypes identified among the 214 mango isolates. Each of the four MAT1-1-2 genotypes had been identified previously (Harrington et al. 2014). Of the 214 studied isolates from mango tested using PCR, only 161 were confirmed to have the MAT1-2-1 gene. Many of the new isolates were single-spored, and care was not taken to retain only the self-fertile, MAT2 strains (some recovered progeny switched mating type and lost the MAT1-2-1 gene). An alignment of 1,139 characters of the MAT12-1 gene showed 16 characters varying, and 10 different MAT1-2-1 genotypes were found among the 161 analyzed isolates.

These mating type genes are tightly linked and are not subjected to normal crossover events, and their combined sequences produce robust phylogenetic trees for the $C$. fimbriata complex (Harrington et al. 2014). The combined dataset of MAT1-1-2 and MAT1-2-1 sequences of mango isolates and other representatives of the LAC had an alignment of 2172 characters: 1743 were constant, 352 were parsimony-uninformative, and 76 were parsimony informative. MP analysis found a single tree of 455 steps (Fig. 5), with $\mathrm{HI}=0.0384$, $\mathrm{CI}=0.9616, \mathrm{RC}=0.9232$, and $\mathrm{RI}=0.9168$. Evolution model $\mathrm{HKY}+\mathrm{G}$ was selected and incorporated into the Bayesian analysis, which produced a tree of identical topology to the MP tree. The other species in the $\mathrm{LAC}(C$. platani, C. colombiana, and $C$. cacaofunesta $)$ were each well supported and found at the base of the tree, and the branch representing $C$. fimbriata had bootstrap support of $86 \%$ and posterior probability of 1.0 (Fig. 5).

Basal within the $C$. fimbriata subclade was a branch ( $84 \%$ bootstrap support and posterior probability of 1.0) comprising mango isolates from Eastern Rio de Janeiro (all 20 isolates had sequence MAT5a), Colocasia isolates from São Paulo, and a Eucalyptus isolate from Paraná. All 25 isolates from Oman and 13 from Pakistan had the MAT7 genotype, which was placed among other Brazilian isolates of $C$. fimbriata and closest to mango isolate C2092 from Western Rio de Janeiro (Fig. 5). Isolate C1688 (=CBS 11472), the ex-type of

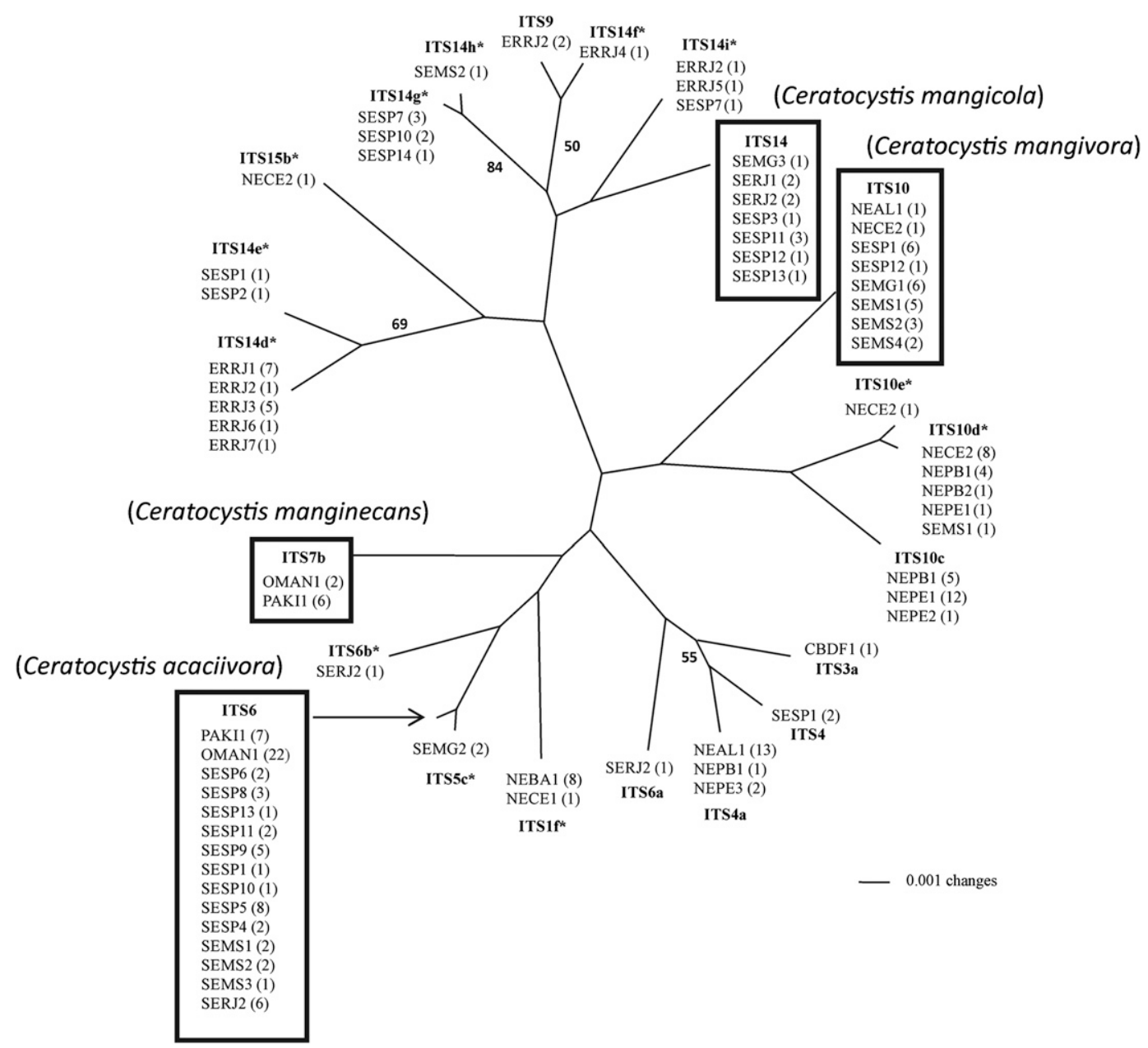

Fig. 2. An unweighted pair group method, arithmetic mean dendrogram of the genetic relatedness of internal transcribed spacer (ITS) rDNA genotypes (sequences) of Ceratocystis fimbriata from Mangifera indica (mango). Ten of the ITS genotypes had been reported by Harrington et al. (2014), with 12 new ITS genotypes designated by unique letters and an asterisk. The names of four previously described species (Tarigan et al. 2011; van Wyk et al. 2007, 2011a) based on distinct ITS sequences are indicated in parentheses above boxes. The locations (Fig. 1) where the ITS genotype was identified are followed by the number of isolates from that location in parentheses. Bootstrap values are shown alongside the branches. Scale bar indicates genetic distance. 
C. mangicola (van Wyk et al. 2011a), had the MAT3b genotype. Isolate C994 (=CBS 600.70), on which the name $C$. mangivora was based (van Wyk et al. 2011a), had the MAT4a genotype (Fig. 5). However, other mango isolates with ITS rDNA sequences representing $C$. mangivora, $C$. mangicola, and $C$. acaciivora each had two or more mating type sequences that were found scattered throughout the C. fimbriata subclade (Fig. 5).

Multigene phylogeny. Forty isolates representing the sequence diversity of mango isolates were selected for multigene phylogenetic analyses combining $\beta$-tubulin, TEF- $1 \alpha$, and mating type sequences. A total of 20 different four-gene genotypes were identified among the mango isolates. Another 19 isolates from other hosts representing the diversity of the LAC and C. variospora as the outgroup taxon were included in the combined dataset. The partition homogeneity test conducted for the four gene regions resulted in $P=0.01$, which is considered low (Cunningham 1997). Nonetheless, an analysis of the combined dataset produced 138 trees of 633 steps, and the trees generally were similar in topology to the more robust MP tree from analysis of the mating type genes alone (Fig. 5). Thus, the topology of the combined tree appeared to be governed by the variation in mating type sequences, and the combined tree is not shown.

Mating experiments. In attempts to identify biological species among mango isolates, fresh tester strains of opposite mating type derived from isolates from each of three regions of Brazil, an isolate

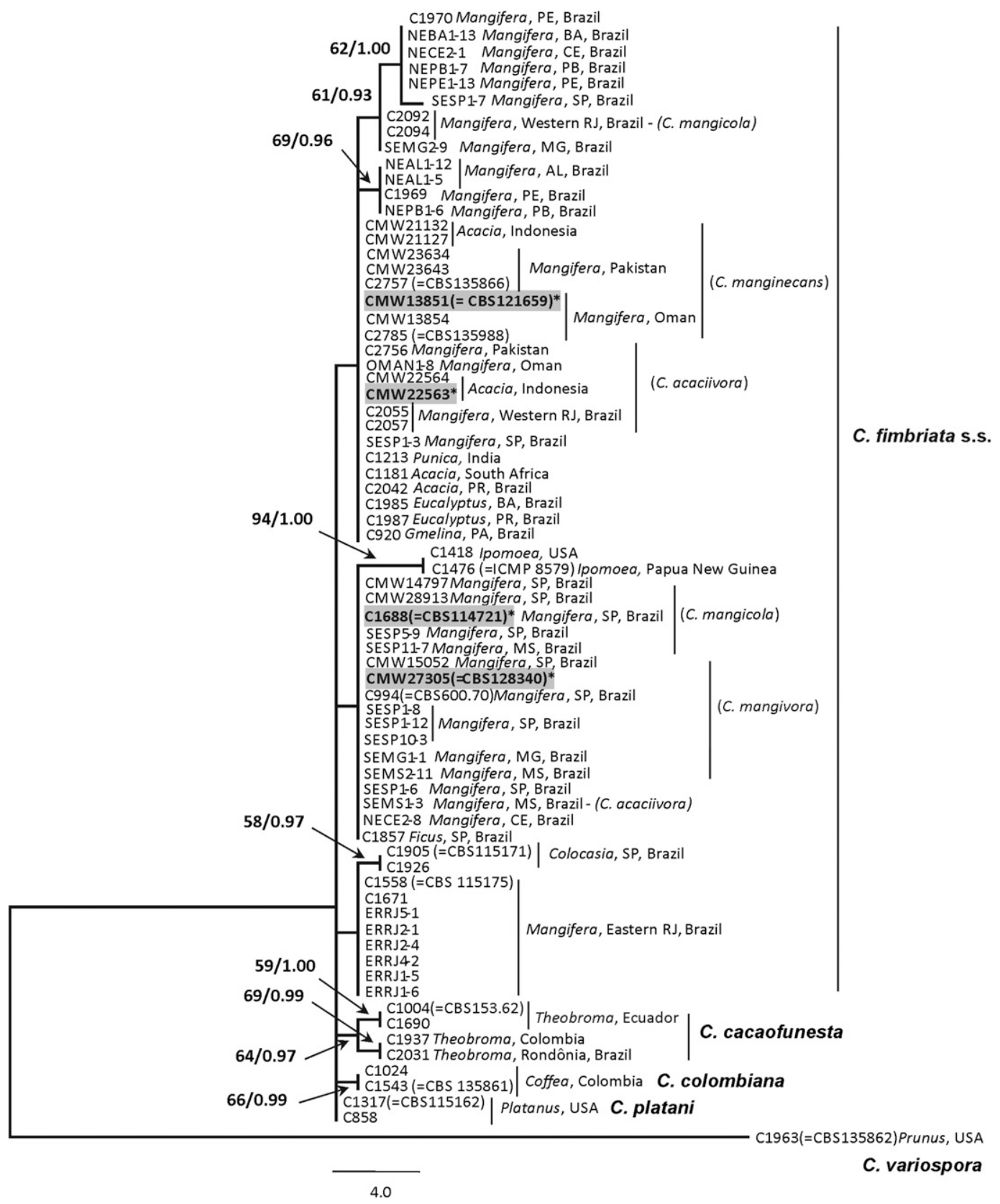

Fig. 3. In total, 1 of 204 trees of 55 steps based on maximum parsimony analysis of sequences of a portion of the $\beta$-tubulin gene of the Latin American Clade (LAC) of the Ceratocystis fimbriata complex. Bootstrap values greater than 50\%/posterior probability values greater than 0.9 are indicated on appropriate branches. Isolate numbers are followed by host genus, (abbreviation for Brazilian state, where appropriate), and country. Sequences taken from the holotype of four previously described species on mango (Tarigan et al. 2011; van Wyk et al. 2007, 2011a) are shaded and indicated with an asterisk, and other isolates representing those species based on distinct internal transcribed spacer sequences are indicated in parentheses to the right of the isolate information. Besides $C$. fimbriata, the other accepted species in the LAC are C. platani, C. cacaofunesta and C. colombiana (Harrington et al. 2014). Isolate numbers are based on sample locations (Fig. 1) or are from the collection stored at Iowa State University (C) or the Centraalbureau voor Schimmelcultures (CBS). The tree was rooted to C. variospora in the North American Clade (isolate C1963). Scale bar indicates number of base changes. 
from Oman, and an isolate from sweet potato successfully crossed with each other in at least one of the two mating experiments (Table 1). In most of the successful, interfertile (I) crosses, there were many fully developed perithecia within a week, with an accumulation of a large, opaque, creamy ascospore masses on the top of each perithecial neck (Fig. 6). However, some of the MAT1 female tester strains performed poorly in crosses, perhaps through loss of femaleness (few protoperithecia produced) (Ferreira et al. 2010). Ascospore masses from crosses were streaked on MYEA, and individual colonies from fully interfertile crosses produced colonies of the mycelial morphology of both the male and female tester strains, demonstrating that the ascospore masses were not due to a selfing.

In contrast, none of the MAT2-male tester strains from mango successfully crossed with MAT1 tester strains of $C$. platani or C. cacaofunesta. In some of these interspecific crosses, only a few perithecia were produced and the ascospore masses from these perithecia were watery, not creamy. Microscopic examination showed aborted asci in the perithecial centrum, and the ascospores were misshapen (Fig. 6), suggesting a postzygotic barrier to meiosis. Consistent with earlier studies (Engelbrecht and Harrington 2005; Ferreira et al. 2010; Harrington and McNew 1997, 1998; Johnson et al. 2005), watery ascospore masses were considered indicative of an interspecific hybrid cross $(\mathrm{H})$.

Morphology. All field isolates from mango appeared identical in culture morphology, with similar growth rates and mycelial pigmentation on MYEA. Cultures were initially white or pale brown, turning to dark brown after 5 to 7 days, the agar underneath turned dark brown (Rayner 1970), and the cultures had a banana-like odor. Mango isolates from the three regions of Brazil and Oman were microscopically examined and found to be indistinguishable from each other and sweet potato isolates (Table 2). Bases of perithecia were superficial to partially immersed, black or dark brown, globose, unornamented or

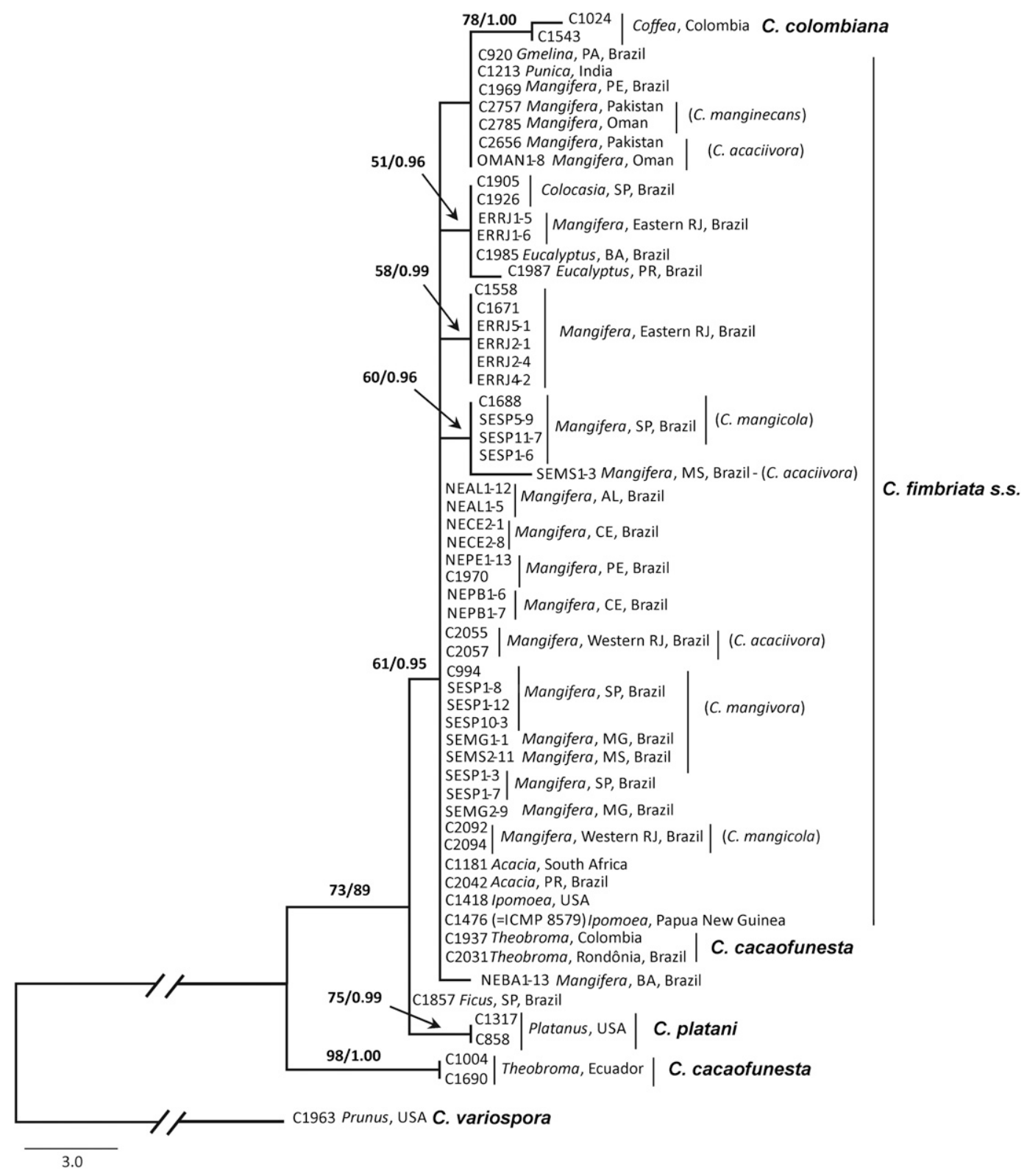

Fig. 4. One of six most parsimonious trees of 74 steps of representatives of the Latin American Clade (LAC) of the Ceratocystis fimbriata complex based on a portion of the TEF- $1 \alpha$ gene. Bootstrap values greater than 50\%/posterior probability values greater than 0.9 are indicated on appropriate branches. Isolate numbers are followed by host genus, abbreviation for Brazilian state (where appropriate), and country. The names of four previously described species on mango (Tarigan et al. 2011; van Wyk et al. 2007, 2011a) based on distinct internal transcribed spacer sequences are indicated in parentheses to the right of the isolate information. Besides C. fimbriata, the other accepted species in the LAC are C. platani, C. cacaofunesta, and C. colombiana (Harrington et al. 2014). The tree was rooted to C. variospora in the North American Clade (isolate C1963). Scale bar indicates number of base changes. 
with undifferentiated hyphae attached. The necks were black or dark brown, slender, with ostiolar hyphae that were hyaline and divergent or convergent. Ascospores had a hat-shaped brim and varied little in size. Endoconidiophores were of two types, one flask-shaped, hyaline to pale brown, septate, producing chains of cylindrical, hyaline endoconidia; and the other endoconidiophore type was less common, usually shorter, not tapering, producing chains of hyaline, doliform (barrel-shaped) endoconidia. Aleurioconidia were produced singly or basipetally in chains, thick-walled, pale brown to dark brown, ovoid or obpyriform, smooth, and similar in size among the studied isolates.

Microsatellite variation in populations. Of the 14 microsatellite loci, all but locus CAG900 were polymorphic among the 214 mango isolates (Table 3). At some locations only one, two or three isolates were obtained, and these were not included in the population analyses, leaving 19 mango populations (Table 4), which roughly separated into the four geographic regions in the UPGMA tree (Fig. 7). There were 57 microsatellite genotypes (unique combination of alleles), and 13 of those (MSAT1-MSAT13) were found in more than one population. The UPGMA tree constructed using the 57 genotypes also tended to separate most of the mango genotypes into the four regional groups (Fig. 8). Further, an AMOVA suggested highly differentiated populations, with more than half of the variation attributed to variation among the four regional groups (Table 5). Within each of the three mango regions in Brazil, more variation was attributable to variation among populations than within populations, with the greatest population differentiation in the Northeast (64\%) and the least in the Southeast (56\%) (Table 5).

Isolates obtained from Oman and Pakistan showed variation only for locus CAA38, which had seven different alleles, and locus CAA9, which had two different alleles (Table 3). Allele CAA9-211 was found in just one isolate. Microsatellite genotype MSAT7 dominated in both countries (Fig. 8), and this appears to be the same genotype earlier identified in Oman and Pakistan using the same markers (Al Adawi et al. 2014). The genotypic diversity value $(G)$ for the 38 isolates from Oman and Pakistan was only 4.40 (maximum possible value of 16 for the regions), and the gene diversity value $(H)$ was only 0.04 , compared

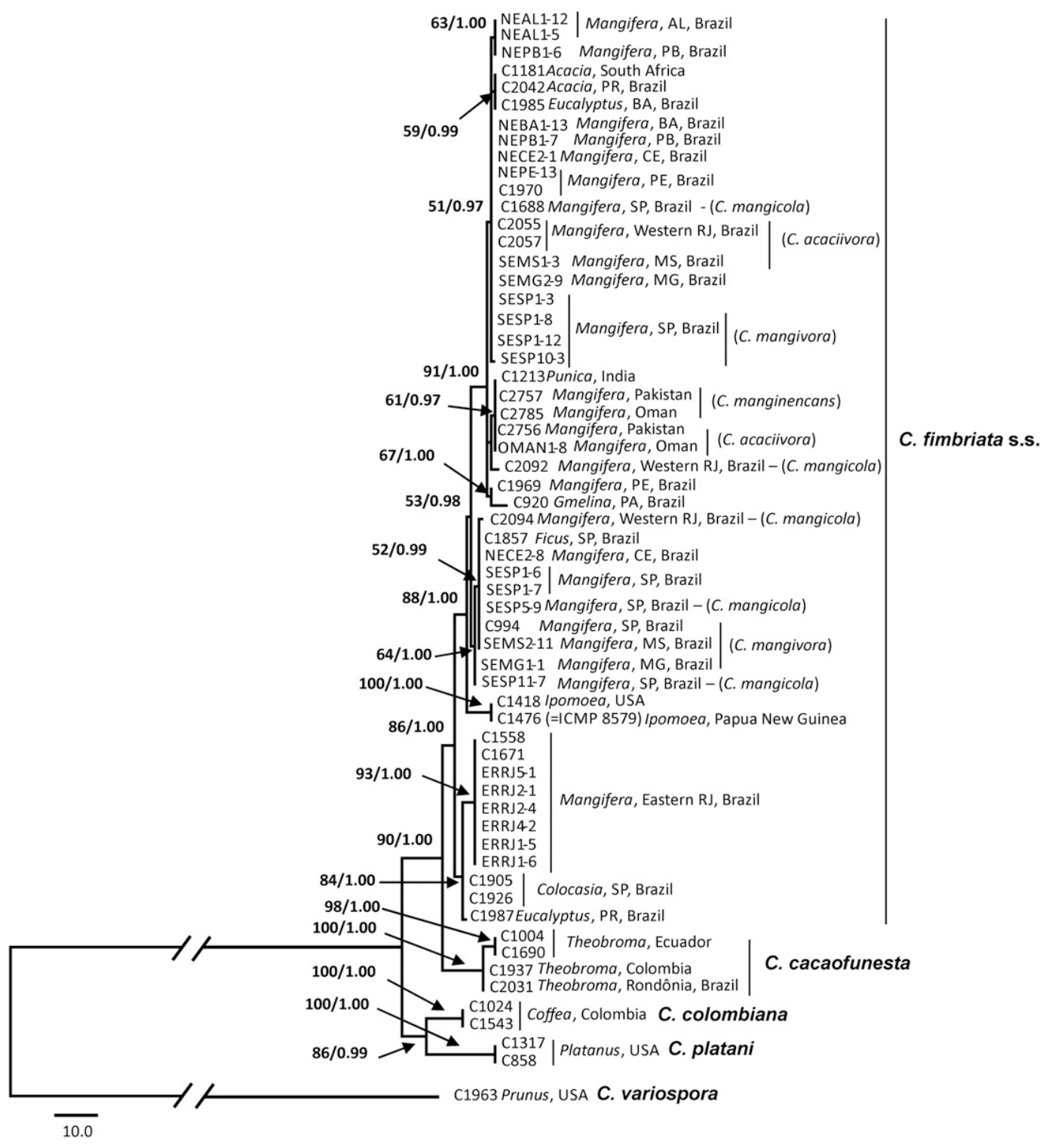

Fig. 5. The single most parsimonious tree of 455 steps based on portions of the MAT1-1-2 and MAT1-2-1 mating type genes for representatives of the Latin American Clade (LAC) of the Ceratocystis fimbriata complex. Bootstrap values greater than $50 \%$ posterior probability values greater than 0.9 are indicated on appropriate branches. Isolate numbers are followed by host genus, abbreviation for Brazilian state (where appropriate), and country. The names of four previously described species on mango (Tarigan et al. 2011; van Wyk et al. 2007, 2011a) based on distinct internal transcribed spacer sequences are indicated in parentheses to the right of the isolate information. Besides C. fimbriata, the other accepted species in the LAC are C. platani, C. cacaofunesta, and C. colombiana (Harrington et al. 2014). The tree was rooted to C. variospora in the North American Clade (isolate C1963). Scale bar indicates number of base changes. 
with the respective values of 5.0 and 0.13 for the Eastern Rio de Janeiro populations, 6.0 and 0.29 for the Southeastern populations, and 9.4 and 0.43 for the Northeastern populations (Table 4).

Consistent with the phylogenetic analyses (Figs. 3 to 5), the five Eastern Rio de Janeiro microsatellite genotypes were closely related (Fig. 8) and the populations similar to the Colocasia population (Fig. 7). Relatively few microsatellite alleles were found in Eastern Rio de Janeiro (Table 3), and three of the five genotypes were found in more than one population (Fig. 8). The five isolates sampled from a single, large plantation (ERRJ3) were genetically identical (Table 4).

The limited variation in Eastern Rio de Janeiro and the near uniformity of Oman and Pakistan populations contrasted sharply with the Eucalyptus populations from three plantations in Bahia and Minas Gerais, which were included as representatives of natural, soilborne populations of $C$. fimbriata (Ferreira et al. 2011, 2013). The three Eucalyptus populations were related to each other (Fig. 7), but their combined populations had high values of $G$ and $H$ (12.5 and 0.34 , respectively), comparable only to the combined mango populations in Northeastern Brazil (Table 4).

Although the Northeastern populations had microsatellite alleles that were similar to those in the Southeast (Table 3), the Northeastern populations showed greater gene and genotypic diversity (Tables 4), and microsatellite genotypes found in the Northeast were rarely found in more than one population (Fig. 8). Only four of the 25 genotypes from Northeastern Brazil were found in more than one Northeastern population (Fig. 8). One isolate from the Southeastern population SEMS1 grouped with Northeastern genotypes, one isolate from NECE1 grouped with Southeastern genotypes, and one isolate from NECE2 had the MSAT12 genotype, which was found in five isolates from two Southeastern plantations (Fig. 8). Aside from the NECE2 isolate, all of the mango isolates from the Northeast had the MAT3b or MAT3c mating type sequence (Fig. 8), showing near uniformity in these genes while the neutral population markers showed a wide variety of alleles (Table 3) in a diversity of combinations (Fig. 8).

The population in and around Seropédica (SERJ2) was the most variable of the Southeastern populations in microsatellite alleles, perhaps because SERJ2 comprises a mixture of introduced genotypes (Ferreira et al. 2010; Harrington et al. 2014). It had relatively high genotypic and gene diversity values (Table 4), as well as four ITS sequences (Fig. 7), including the ITS6 genotype and the mixed (intragenomic) ITS sequences found in some isolates in Oman and Pakistan. The microsatellite genotypes from Western Rio de Janeiro
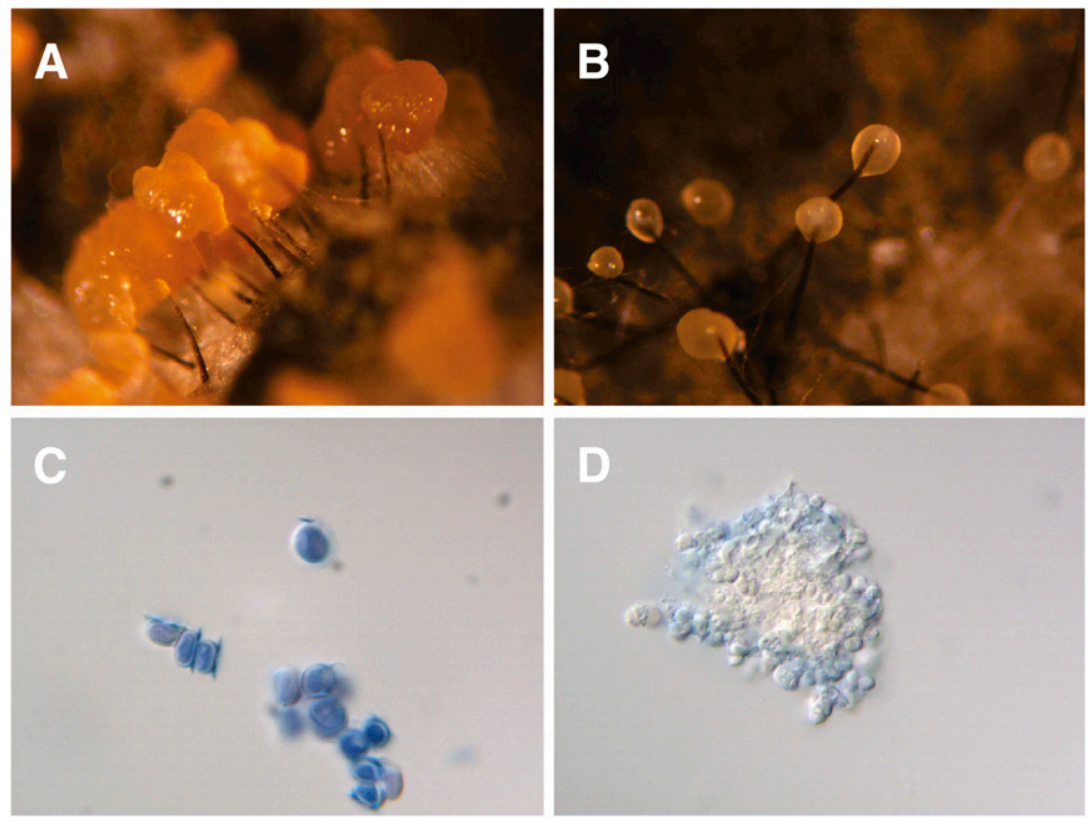

Fig. 6. A and B, Perithecia and ascospore masses and $\mathbf{C}$ and $\mathbf{D}$, ascospores from an interfertile cross (A and C) between two compatible Mangifera indica (mango) strains of $C$. fimbriata (isolates NEBA1-10 $\times$ OMAN8-1) and a hybrid, interspecific cross between a mango strain of C. fimbriata (isolate SESP5-1) and a Platanus strain of $C$. platani (isolate C1317) showing small watery ascospore masses (B), aborted asci, and misshapen ascospores (D).

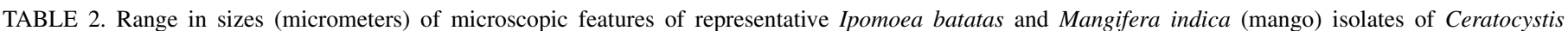

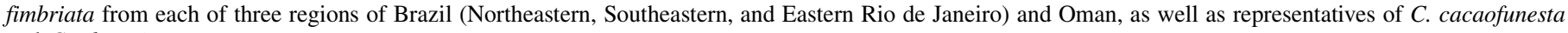
and C. platani

\begin{tabular}{|c|c|c|c|c|c|c|c|c|}
\hline $\begin{array}{l}\text { Region or previous } \\
\text { described species }\end{array}$ & Isolate & $\begin{array}{l}\text { Base of perithecia } \\
\text { (height } \times \text { width) }\end{array}$ & Ascospores & $\begin{array}{c}\text { Length of } \\
\text { perithecial } \\
\text { neck }\end{array}$ & $\begin{array}{c}\text { Length of } \\
\text { ostiolar } \\
\text { hyphae }\end{array}$ & $\begin{array}{l}\text { Cylindrical } \\
\text { conidia }\end{array}$ & $\begin{array}{l}\text { Doliiform } \\
\text { conidia }\end{array}$ & Aleuroconidia \\
\hline \multirow[t]{2}{*}{ Southeastern Brazil } & SEMS2-11 ${ }^{\mathrm{a}}$ & $115-190 \times 105-195$ & $4-6 \times 3-5$ & $395-655$ & $37-60$ & $11-29 \times 3-5$ & $8-11 \times 5-6$ & $10-15 \times 8-10$ \\
\hline & SESP5- $1^{\mathrm{b}}$ & $125-195 \times 115-185$ & $4-6 \times 3-5$ & $370-565$ & $37-55$ & $10-26 \times 3-5$ & $7-9 \times 5-6$ & $10-14 \times 9-12$ \\
\hline Northeastern Brazil & NEBA1-10 & $125-250 \times 125-280$ & $4-6 \times 3-5$ & $260-680$ & $30-52$ & $14-20 \times 3-5$ & $7-9 \times 4-6$ & $8-15 \times 7-12$ \\
\hline Eastern Rio de Janeiro & ERRJ4-2 & $145-230 \times 150-250$ & $5-6 \times 4-5$ & $430-620$ & $41-64$ & $12-30 \times 3-5$ & $7-11 \times 4-6$ & $8-14 \times 8-12$ \\
\hline Oman & OMAN5-7c & $185-260 \times 165-245$ & $5-6 \times 3-5$ & $367-645$ & $20-38$ & $11-30 \times 4-5$ & $7-10 \times 4-5$ & $8-15 \times 7-12$ \\
\hline C. fimbriata & $\mathrm{C} 1418^{\mathrm{d}}$ & $120-250 \times 110-250$ & $5-7.5 \times 3.5-5$ & $440-770$ & $20-120$ & $9-33 \times 3-5$ & Not seen & $11-16 \times 6.5-12$ \\
\hline C. cacaofunesta & $\mathrm{C} 1983^{\mathrm{d}}$ & $100-275 \times 95-305$ & $4.5-6.5 \times 3.5-5.5$ & $310-1,010$ & $30-125$ & $8-40 \times 2.5-5$ & Not determined & $10-20 \times 3.5-11.5$ \\
\hline C. platani & $\mathrm{C} 1317^{\mathrm{d}}$ & $175-290 \times 175-290$ & $4-6.5 \times 3-4.5$ & $535-835$ & $20-90$ & $11-22 \times 3-5$ & $6-10 \times 3.5-5$ & $10-20 \times 6-12$ \\
\hline
\end{tabular}

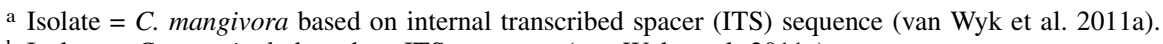

b Isolate $=C$. mangicola based on ITS sequence (van Wyk et al. 2011a).

c Isolate $=C$. acaciivora based on ITS sequence (Tarigan et al. 2011).

d Measurements from Engelbrecht and Harrington (2005). Isolate C1418 was from Ipomoea batatas. 
varied greatly from each other but were generally similar to other genotypes from the Southeast (Fig. 8). Of 13 isolates from Western Rio de Janeiro, 11 had mating type sequences typical of the Northeast (MAT3a and MAT3b), one (C2094) had the MAT4c sequence typical of the Southeastern populations, and one (C2092) had the MAT4b sequence that was similar to the MAT7 sequence found in Oman and Pakistan (Fig. 5).

Widespread microsatellite genotypes. Outside of the 13 Western Rio de Janeiro isolates and one isolate from Mato Grosso do Sul, the other 80 isolates from Southeastern Brazil were closely related to each other, and most had one of two dominant genotypes (Fig. 8). Twenty-four isolates from eight locations had the MSAT1 genotype (Fig. 8), and 37 isolates from 12 locations had the MSAT2 genotype (Fig. 8). The isolate from the holotype of $C$. mangicola (C1688 = CBS 114721) had the MSAT1 microsatellite markers and isolate C994 (=CBS 600.70), which was among the isolates used to initially describe C. mangivora (van Wyk et al. 2011a), had the MSAT2 microsatellite markers.

It was hypothesized that the names $C$. mangicola and $C$. mangivora were based on genotypes of $C$. fimbriata that had been distributed in

TABLE 3. Estimated sizes (base pairs) of alleles of 14 microsatellite loci found in Mangifera indica (mango) populations of Ceratocystis fimbriata in four regions, with the number of isolates tested in each region shown in parentheses

\begin{tabular}{|c|c|c|c|c|}
\hline Microsatellite locus & Southeastern Brazil (94) & Northeastern Brazil (61) & $\begin{array}{l}\text { Eastern Rio de } \\
\text { Janeiro (20) }\end{array}$ & Oman/Pakistan (38) \\
\hline AAG8 & $174,177,180,183$ & 174,177 & 186,198 & 177 \\
\hline AAG9 & $391,397,400$ & $397,400,403,406$ & 391 & 403 \\
\hline CAA9 & 175,205 & $175,178,205$ & 197,223 & 211,226 \\
\hline CAA10 & $128,131,134$ & 128,134 & 128 & 122 \\
\hline CAA15 & 321,324 & $306,321,324$ & 321,330 & 324 \\
\hline CAA38 & $146,201,214,238,247$ & $146,153,162,174,183,202,211,214,223$ & 168,211 & $214,312,321,334,340,349,357$ \\
\hline CAA80 & $311,317,320,323,329,333$ & $288,317,320,323,329,333$ & 311 & 305 \\
\hline CAG5 & $298,317,320$ & 317,320 & 323,326 & 317 \\
\hline CAG15 & $259,286,292$ & $268,286,292,295$ & 277,286 & 274 \\
\hline CAG900 & 194 & 194 & 194 & 194 \\
\hline CAT1 & 257,261 & $254,257,260,261$ & 248 & 254 \\
\hline CAT12 & 374,377 & $371,374,377$ & 380 & 374 \\
\hline GACA6K & $215,219,221$ & 215,221 & 219 & 215 \\
\hline GACA60 & 187,200 & 187 & 187,221 & 187 \\
\hline
\end{tabular}

TABLE 4. Genetic diversity of Mangifera indica (mango) populations of Ceratocystis fimbriata from Brazil, Oman, and Pakistan and representative Eucalyptus and Colocasia populations of C. fimbriata from Brazil based on 14 microsatellite loci

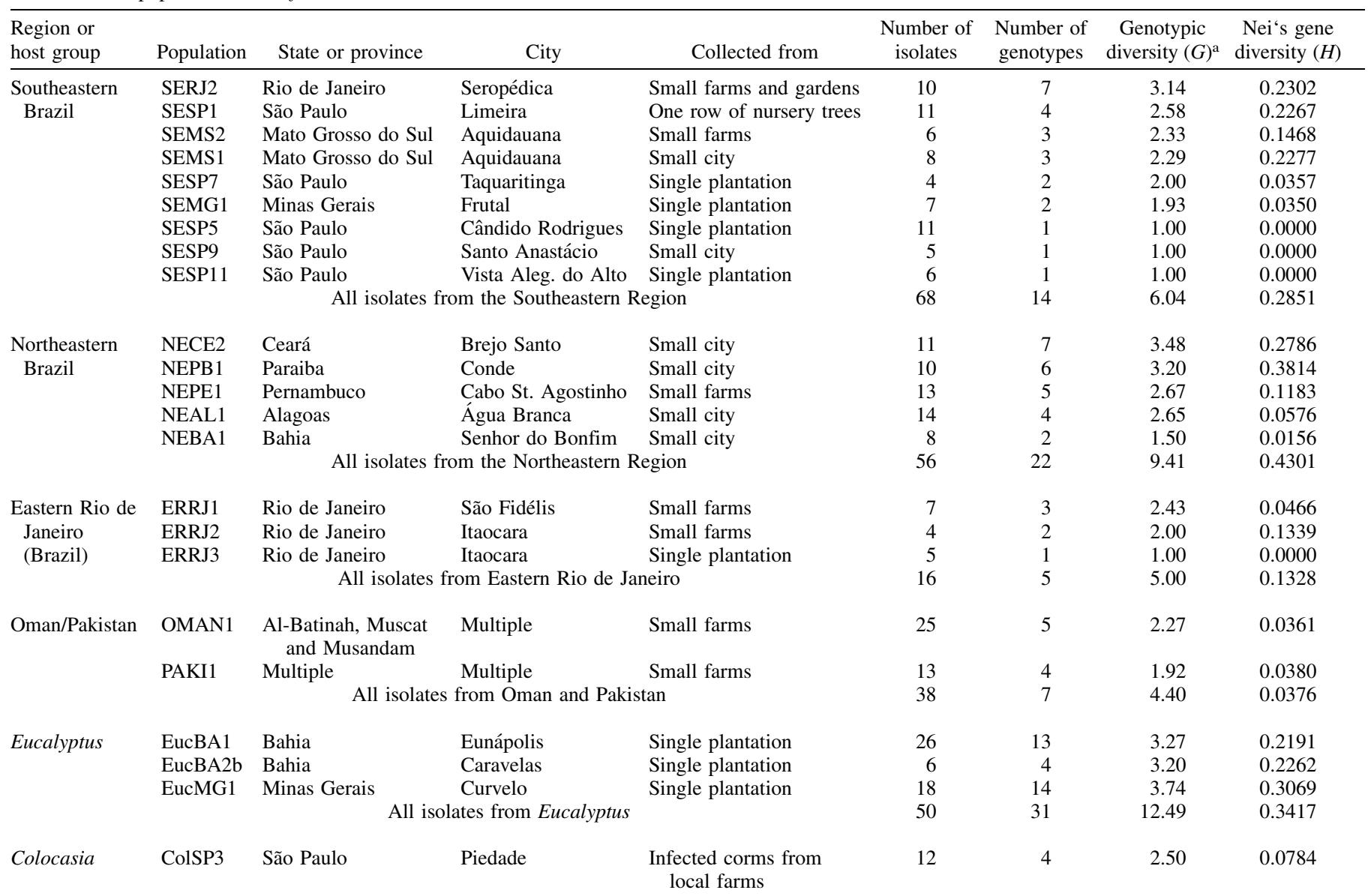

${ }^{a}$ Stoddart and Taylor's genotypic diversity, with rarefaction. Values of $\mathrm{G}$ with rarefaction for individual populations ranged from 1.0 (only one genotype in the population) to a maximum value of 4.0 (each isolate in the population of a different genotype). Maximum values for region or host groups ranged from 1 to16. 
nursery stock (Harrington et al. 2014), and attempts were made to find the pathogen in commercial nurseries in the largest nursery region in São Paulo. Population SESP1 was a sampling of 11 isolates from a row of mango trees in an abandoned nursery near Limeira (Table 4). Four microsatellite genotypes, including MSAT1/C. mangivora, MSAT2/C. mangicola and MSAT11 (Fig. 8), as well as four ITS genotypes (Fig. 7) and two mating type sequences (Fig. 8), were recovered from the row of diseased trees. The trees appeared to have been undisturbed since planting some years before, and they were without evidence of stem wounding or attack by bark beetles. The trees were apparently infected from soilborne inoculum because the infections arose from the roots.

All of the Southeastern populations except SERJ2 from Western Rio de Janeiro had lower genetic diversity values than the nursery population SESP1, and each was dominated by the MSAT1 or MSAT2 genotypes found in the nursery (Table 4, Fig. 8). The four plantation populations in Southeastern Brazil were nearly uniform and had only genotypes MSAT1, MSAT2, and MSAT12, the latter differing from
MSAT1 at only one locus. The isolates recovered from plantations SESP7 and SEMG1 had only the MSAT1 and MSAT12 genotypes, in roughly equal proportions, and only the MSAT2 genotype was recovered from plantations SESP5 and SESP11 (Table 4, Fig. 8). The city population from Santo Anastácio (SESP9) also had only the MSAT2 genotype (Table 4).

Isolates with related microsatellite genotypes generally had identical or similar mating type sequences, except in the Southeastern region (Fig. 8). With the exception of the Mato Grosso do Sul populations, isolates of the MSAT1 genotype had one of the Northeast mating type sequences (MAT3b), while isolates of the MSAT2 genotype had one of the Southeast mating type sequences (MAT4a or MAT4d) (Fig. 8).

\section{DISCUSSION}

There was no evidence of cryptic species among mango isolates of $C$. fimbriata. The new species names were primarily based on

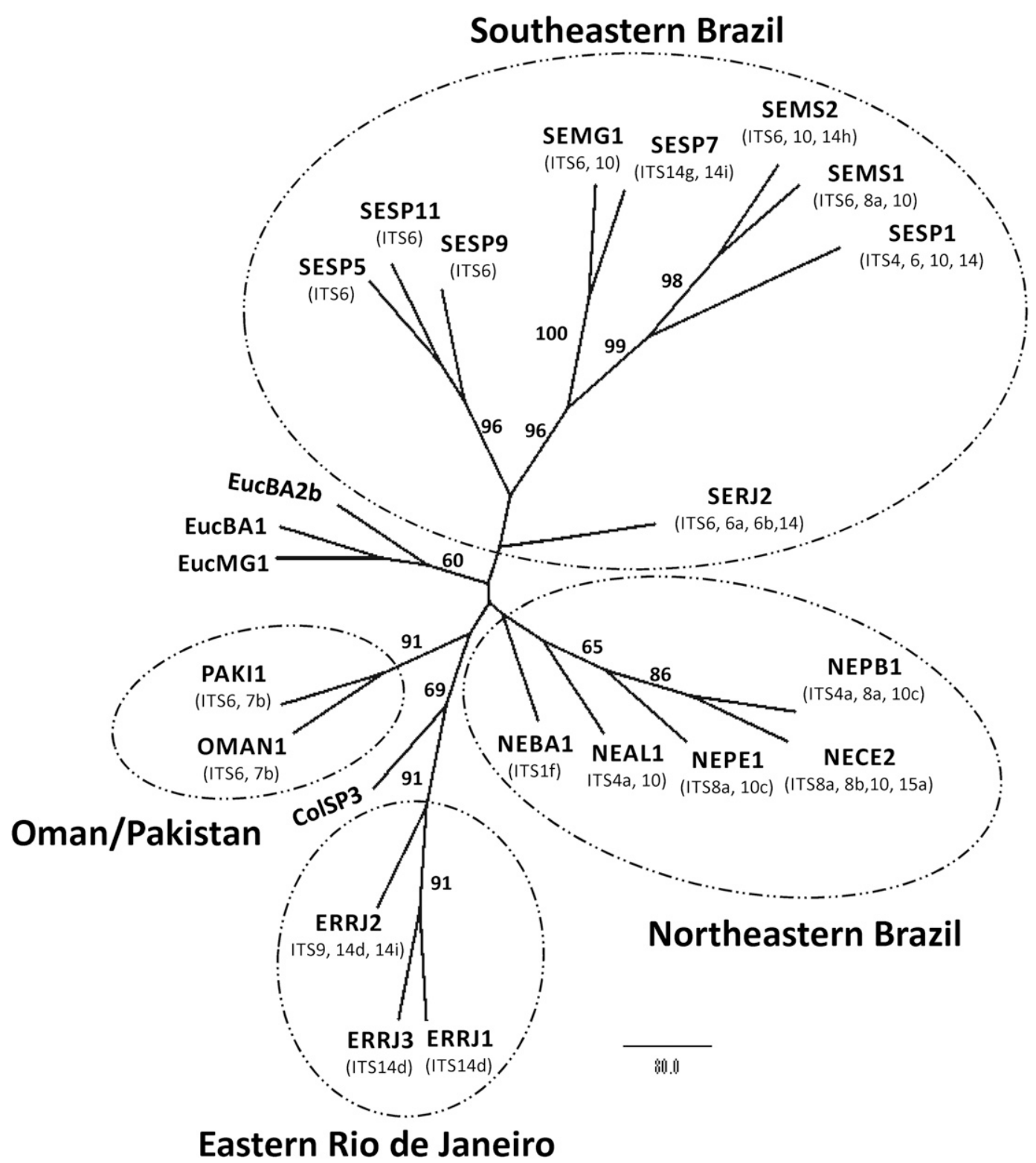

Fig. 7. Dendrogram of the relatedness of populations of Ceratocystis fimbriata from Mangifera indica (mango), Eucalyptus (EucBA1, EucBA2b, and EucMG1), and Colocasia (ColSP3) generated by unweighted pair group method, arithmetic mean based on allele frequencies (Nei's gene diversity) of 14 microsatellite loci. Bootstrap values greater than 50\% are indicated alongside the branches. Dotted and dashed lines encircle Mangifera populations from three regions of Brazil (Northeastern, Southeastern, and Eastern Rio de Janeiro), and the Oman/Pakistan region. State designations for the Brazilian populations are AL = Alagoas; BA = Bahia; $\mathrm{CE}=$ Ceará, $\mathrm{DF}=$ Distrito Federal; $\mathrm{MG}=$ Minas Gerais; $\mathrm{MS}=$ Mato Grosso do Sul; $\mathrm{PA}=$ Pará; $\mathrm{PB}=\mathrm{Paraíba} ; \mathrm{PE}=\mathrm{Pernambuco} ; \mathrm{PR}=\mathrm{Paraná} ; \mathrm{RJ}=\mathrm{Rio}$ de Janeiro; and SP = São Paulo. The internal transcribed spacer rDNA genotypes found in the population are in parentheses. Scale bar indicates genetic distance. 
unique ITS sequences, but phylogenetic analyses of gene coding regions placed the four recently described species among other Brazilian populations of $C$. fimbriata from mango and other hosts, as well as the sweet potato strain, on which the species name $C$. fimbriata was based. No morphological variation was seen among representative mango isolates. Interfertility tests demonstrated that representative mango isolates are within the same biological species as Brazilian isolates from other hosts and the sweet potato strain. Microsatellite markers showed that populations of $C$. fimbriata on mango are highly differentiated within and across regions, and natural populations rarely shared microsatellite genotypes. On the other hand, representatives of the recently described species had the most common and widespread microsatellite genotypes on mango, supporting the hypothesis that the recently described species were based on introduced strains of $C$. fimbriata.

The strongest case for a genealogical species within $C$. fimbriata was the closely related populations of mango isolates from Eastern Rio de Janeiro, which grouped with Colocasia isolates from São Paulo (Ferreira et al. 2010; Harrington et al. 2005) in phylogenic analyses and in microsatellite makers. These mango and Colocasia

Mating haplotype $3 \mathrm{~b}$ and $3 \mathrm{c}$

Mating haplotype $4 \mathrm{a}, 4 \mathrm{c}$ and $4 \mathrm{~d}$

Mating haplotype $5 a$

Mating haplotype 7
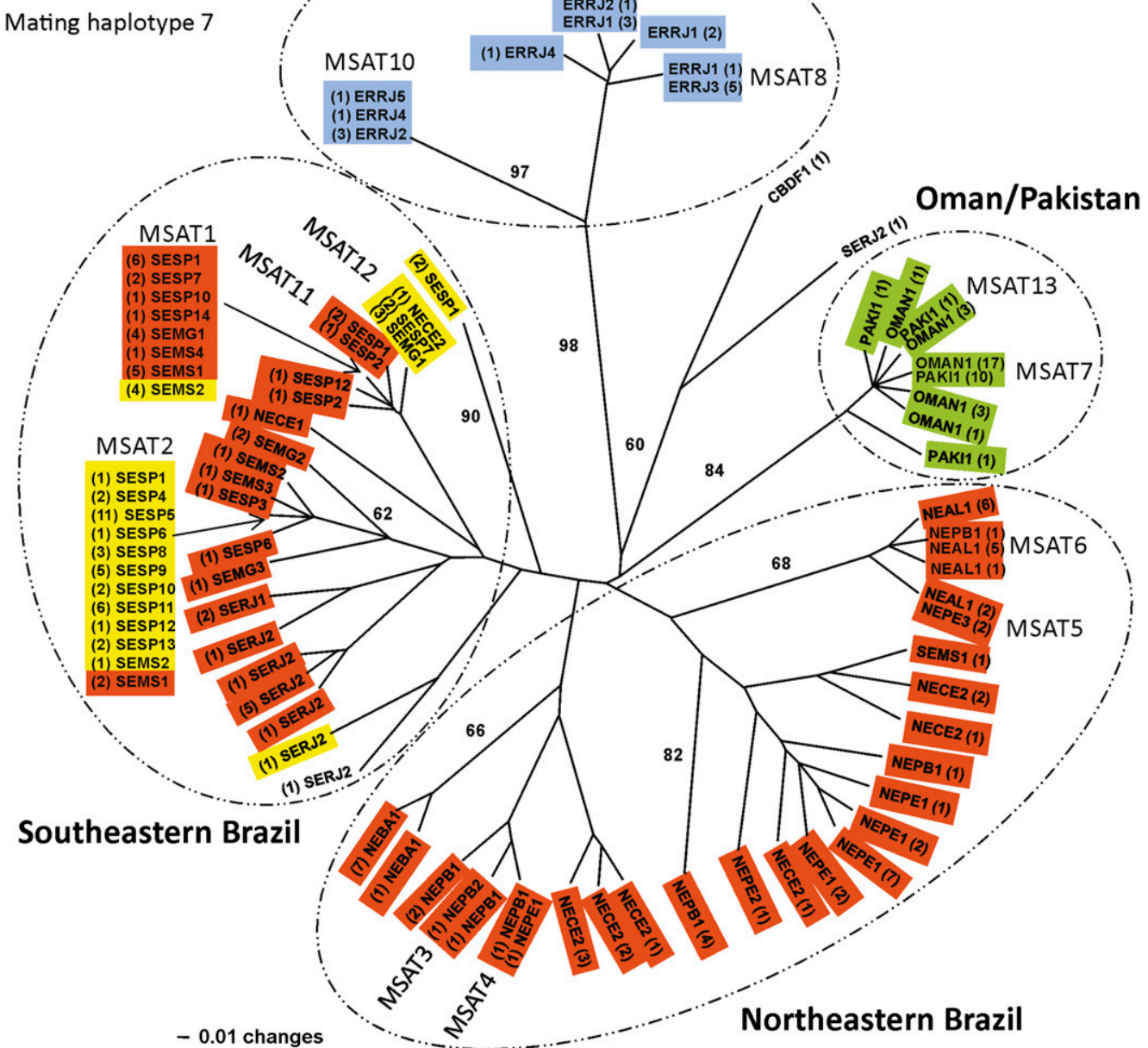

Fig. 8. An unweighted pair group method, arithmetic mean dendrogram of genotypes of Ceratocystis fimbriata from Mangifera indica (mango) based on alleles of 14 microsatellite loci (Nei's gene diversity). Bootstrap values are shown alongside the branches. The number of isolates with that genotype from each population is in parentheses. Thirteen genotypes found in more than one population are designated by "MSAT" followed by a number. Microsatellite genotypes encircled by dotted and dashed lines are from one of the three regions of Brazil (Northeastern, Southeastern, and Eastern Rio de Janeiro) or Oman/Pakistan. Related mating type DNA sequences (Fig. 5) of the isolates are color-coded. Scale bar indicates genetic distance.

TABLE 5. Analysis of molecular variance of Mangifera indica (mango) populations of Ceratocystis fimbriata from three regions of Brazil (Northeastern, Southeastern, and Eastern Rio de Janeiro), Oman, and Pakistan based on 14 microsatellite loci

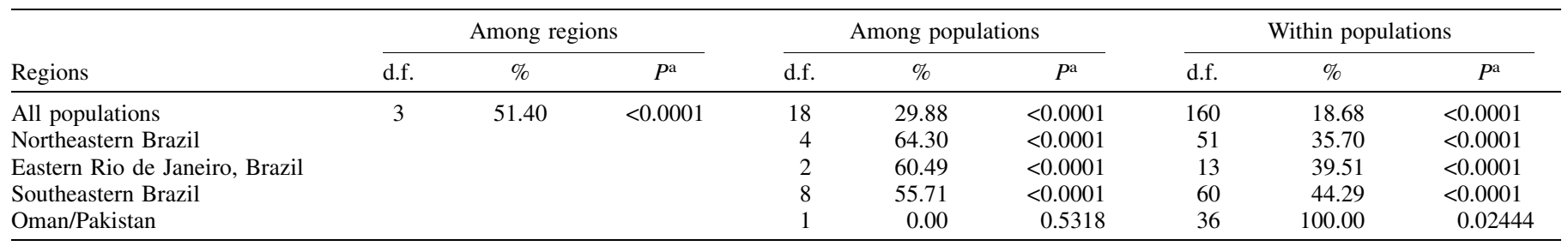

a The $P$ value is for the null hypothesis that there is no significant variation at that level based on 1,023 permutations. 
populations appear to be indigenous to a unique ecological zone, a wet, low-elevation coastal region of Brazil that was formerly Mata Atlântica forest type (Harrington et al. 2014). Most of the other studied populations of $C$. fimbriata from Brazil appear to be native to the generally drier Northeast of Brazil, including the seasonally drier Cerrado and Catinga forest types. Although the populations from Eastern Rio de Janeiro may be geographically isolated and ecologically distinct, they were not morphologically distinguishable from other mango isolates of $C$. fimbriata. Further, isolates from this region do not appear to be host specialized, though mango isolates from Eastern Rio de Janeiro may be particularly aggressive to mango and other nonnative hosts (Baker et al. 2003; Harrington et al. 2011; Silveira et al. 2006). Thus, with no diagnosable phenotypic character, this Eastern Rio de Janeiro lineage is not a phylogenetic species in the traditional sense (Harrington and Rizzo 1999). Further, mango tester strains from this region were fully interfertile in crosses with other mango isolates and the sweet potato tester, as was found with similar mango and Colocasia isolates in an earlier interfertility study (Ferreira et al. 2010). Therefore, a genealogical species recognition concept may distinguish mango and Colocasia isolates from the coastal lowlands as a cryptic species, but the traditional phylogenetic and biological species concepts would recognize it merely as a group of populations.

Species delimitation would ideally be based on understanding of phenotypic variation and population structure (Harrington and Rizzo 1999), but most important fungal pathogens on crop plants are known only by their human-mediated populations. C. fimbriata and closely related species in the LAC present interesting case studies because native and introduced populations have been characterized. Patterns of highly variable native populations versus introduced populations that have gone through genetic bottlenecks have been characterized using the same microsatellite and other markers for C. platani on Platanus spp. (Engelbrecht et al. 2004; Ocasio-Morales et al. 2007), C. cacaofunesta on cacao (Engelbrecht et al. 2007), and C. fimbriata populations on various crops in Brazil (Ferreira et al. 2010). Local populations of C. fimbriata on Eucalyptus that are based on root infections via natural, soilborne inoculum tend to have high gene and genotypic diversity, while local populations based on planting of infected nursery stock are genetically uniform (Ferreira et al. 2011, 2013). Similar evidence suggests that Chinese populations of $C$. fimbriata on pomegranate, Colocasia and other hosts have gone through a genetic bottleneck and may have been introduced on Eucalyptus cuttings from Brazil (Harrington et al. 2015). This is likely the same pathway for the $C$. fimbriata populations on Eucalyptus in South Africa (van Wyk et al. 2006), which are related to Brazilian Eucalyptus isolates and Chinese pomegranate isolates (Harrington et al. 2014, 2015).

On mango, the most genetically variable and distinct populations were found in the Northeast, and mostly depauperate populations with widely shared genotypes were found in other regions. Microsatellite markers showed a highly differentiated population structure in the Northeast, suggesting limited gene flow among populations, consistent with expectations for a homothallic, soilborne pathogen with only limited dispersal by insects and no airborne spores (Ferreira et al. 2010, 2011). However, some local populations showed limited genotypic diversity, and localized spread of genotypes is possible through movement of the pathogen on tools (Harrington 2013) or by the mango bark beetle, Hypocryphalus mangifera (Coleoptera: Scolytinae), a native of Asia that can serve as a vector of $C$. fimbriata in mango (Al Adawi et al. 2006, 2013a; Masood and Saeed 2012; Rossetto and Medeiros 1967). This mango-specific beetle was common at our collection sites in Oman, Eastern Rio de Janeiro, and Northeastern Brazil, where it may be responsible for local spread of genotypes from mango tree to mango tree. However, humans appear to be the most important long-distance vector, especially in movement of infected grafted or otherwise vegetatively propagated material (Engelbrecht et al. 2007; Ferreira et al. 2011, 2013; Harrington 2013; Harrington et al. 2014, 2015). The genetic data suggest that there is only limited movement of $C$. fimbriata among populations in the Northeast, but populations in each of the other regions were dominated by a few widespread microsatellite genotypes, consistent with introductions of the pathogen in grafted mango nursery stock (Rossetto and Ribeiro 1990).

Ceratocystis wilt on mango trees was first noted in the Northeast (Carvalho 1938), where we found that the disease remains restricted to scattered locations on garden and street trees, and there are no confirmed reports in large plantations. Decades later, the disease was recognized in São Paulo (Viégas 1960), where it remains a major cause of mango tree mortality in plantations as well as small cities and small farms in São Paulo and neighboring states. The population on the garden and street mango trees in Western Rio de Janeiro was unique because it appeared to be derived from multiple introductions of genetically diverse strains of $C$. fimbriata, some of which genetically resemble the introduced strains found in Oman, Pakistan, India, and Indonesia (Harrington et al. 2014). But elsewhere in the Southeast, either MSAT1 or MSAT2 or both were recovered from each of the sampled populations.

Only one or two of the widespread microsatellite genotypes were recovered from each of the five studied mango plantations. Consistent with the hypothesis that these plantations or neighboring plantings were established with infected nursery stock, the two dominant genotypes of the Southeast were recovered from a row of abandoned and undisturbed mango plants in the sampled nursery in Limeira. Altogether, the MSAT1 and MSAT2 genotypes were isolated from 61 of the 81 sampled trees and from each population sampled in São Paulo, Mato Grosso do Sul and Minas Gerais. The São Paulo isolates used to originally describe $C$. mangivora and $C$. mangicola (C994 = CBS 600.70, and C1688 = CBS 114721, respectively) (van Wyk et al. 2011a) have the respective MSAT1 and MSAT2 microsatellite markers. Representative isolates of these two genotypes were not distinguished from each other or other $C$. fimbriata populations in our phylogenetic analyses, they were fully interfertile in crosses with other mango isolates and with the $C$. fimbriata tester from sweet potato, and they were not distinguished by morphology, host range or other phenotype.

Consistent with our phylogenetic analyses, Fourie et al. (2015) failed to distinguish representatives of $C$. mangivora and $C$. mangicola by DNA sequence analyses. They recommend retention of the species names because they could distinguish the few studied isolates by single nucleotide polymorphisms, which likely correspond to the microsatellite polymorphisms found in MSAT1 and MSAT2. No other Brazilian strains of $C$. fimbriata were studied by Fourie et al. (2015), but with the wider sampling of mango isolates from Brazil, it is clear that it is not practical to name each genotype of $C$. fimbriata as a new species. Similarly, with the widespread introduction of strains of $C$. fimbriata around the world, it is not practical or informative to name each introduced genotype as a new species, especially if the origin of the introduced strains is not known.

The only confirmed reports of Ceratocystis wilt on mango outside of Brazil are in Pakistan and Oman, and our analyses and those of $\mathrm{Al}$ Adawi et al. (2014) demonstrate that the pathogen population in those countries is dominated by a single microsatellite genotype. Although the exact combination of microsatellite markers and mating type gene sequences were not identified in Brazil, the Oman, Pakistan, and Indian pomegranate isolates are closest to Gmelina isolates from the lower Amazonian state of Pará and mango isolates from Northeastern Brazil and Western Rio de Janeiro. The $\beta$-tubulin and ITS rDNA sequences also tie the Oman, Pakistan and Indian strain to the Ceratocystis wilt pathogen on Acacia spp. in Indonesia and populations of $C$. fimbriata in the Northeast of Brazil, supporting the hypothesis that the introduced population in Oman and South Asia has a South American origin (Harrington et al. 2014), although the pathway of introduction is not clear.

Some isolates from Pakistan, Oman and India have more than one ITS sequence within a single haploid genome (Al Adawi et al. 2013b; Harrington et al. 2014; Naidoo et al. 2013), as was found for 
a mango isolate from Western Rio de Janeiro (Harrington et al. 2014). Such intragenomic variation in ITS sequences may be due to recent crosses between two introduced strains with differing ITS sequences (Harrington et al. 2014). The two most common ITS sequences found among isolates and within genomes in Oman and Pakistan were described as new species, C. manginecans (van Wyk et al. 2007) and C. acaciivora (Tarigan et al. 2011), but clearly they are a single species based on our results and the more extensive phylogenetic analyses by Fourie et al. (2015). Oman isolates were interfertile with other mango isolates from Brazil and the sweet potato tester strain, showing that they are the same biological species as $C$. fimbriata in the strictest sense. Phylogenetic analyses place the Oman, Pakistan, Indian, and Indonesian strain among Brazilian populations of $C$. fimbriata, and lack of morphological distinction precludes recognition of $C$. manginecans or $C$. acaciivora by the traditional phylogenetic species concept.

Recognition of species by genealogical concordance requires inclusion of representative samples from natural populations of the putative new species and relatives (Taylor et al. 2000). Without representatives of native populations, each independently introduced population could appear as a distinct lineage and could be described as a new species. This is especially likely if the natural populations are highly differentiated, as is the case with $C$. fimbriata in Brazil, and the introductions have different geographic origins.

Many new species of other important fungal genera of plant pathogens have been similarly described based solely on humanmediated populations and only minor DNA sequence variation, mostly in ITS sequences. However, species names without distinguishing phenotype carry little useful information, and recognition of each genotype as a new species is becoming impractical. This work with $C$. fimbriata points to the importance of studying natural populations and the use of phenotype in delineating species of fungi, as is done in the naming of species in other groups of organisms (Harrington and Rizzo 1999).

\section{ACKNOWLEDGMENTS}

This research was supported by Vale, CNPq, FAPEMIG, and CAPES. We thank R. G. de Freitas, H. Qiong, L. Qian, D. McNew, L. M. S. Guimarães, R. F. Alfenas, and D. L. Siqueira for technical assistance. We are also grateful to the many individuals who assisted in the collection of isolates, especially M. R. Kazmi, E. A. V. Zauza, and E. L. Furtado.

\section{LITERATURE CITED}

Al Adawi, A. O., Al Jabri, R. M., Deadman, M. L., Barnes, I., Wingfield, B. D., and Wingfield, M. J. 2013a. The mango sudden decline pathogen, Ceratocystis manginecans, is vectored by Hypocryphalus mangifera (Coleoptera: Scolytinae) in Oman. Eur. J. Plant Pathol. 135:243-251.

Al Adawi, A. O., Barnes, I., Khan, I. A., Al Subhi, A. M., Al Jahwari, A. A., Deadman, M. L., Wingfield, B. D., and Wingfield, M. J. 2013 b. Ceratocystis manginecans associated with a serious wilt disease of two native legume trees in Oman and Pakistan. Australas. Plant Pathol. 42: 179-193.

Al Adawi, A. O., Barnes, I., Khan, I. A., Deadman, M. L., Wingfield, B. D., and Wingfield, M. J. 2014. Clonal structure of Ceratocystis manginecans populations from mango wilt disease in Oman and Pakistan. Australas. Plant Pathol. 43:393-402.

Al Adawi, A. O., Deadman, M. L., Rawahi, A. K., Maqbali, Y. M., Al Jahwari, A. A., Ak Saadi, B. A., Al Amri, I. S., and Wingfield, M. J. 2006. Aetiology and causal agents of mango sudden decline disease in Sultanate of Oman. Eur. J. Plant Pathol. 116:247-254.

Baker, C. J., Harrington, T. C., Krauss, U., and Alfenas, A. C. 2003. Genetic variability and host specialization in the Latin American clade of Ceratocystis fimbriata. Phytopathology 93:1274-1284.

Batista, D. C., Terao, D., Barbosa, M. A. G., and Barbosa, F. R. 2008. Seca-damangueira detecção, sintomatologia e controle. Comunicado Técnico 138. Embrapa, Petrolina, PE. http://www.cpatsa.embrapa.br

Carvalho, M. B. 1938. Sobre dois insetos nocivos à mangueira. Bol. Secretaria Agric. Industria Comercio Pernambuco 3:130-132.

Cunningham, C. W. 1997. Can three incongruence tests predict when data should be combined? Mol. Biol. Evol. 14:733-740.
Engelbrecht, C. J. B., and Harrington, T. C. 2005. Intersterility, morphology, and taxonomy of Ceratocystis fimbriata on sweet potato, cacao, and sycamore. Mycologia 97:57-69.

Engelbrecht, C. J. B., Harrington, T. C., Alfenas, A. C., and Suarez, C. 2007. Genetic variation of populations of the cacao wilt pathogen, Ceratocystis cacaofunesta. Plant Pathol. 56:923-933.

Engelbrecht, C. J. B., Harrington, T. C., Steimel, J., and Capretti, P. 2004. Genetic variation in Eastern North American and putatively introduced populations of Ceratocystis fimbriata f. sp. platani. Mol. Ecol. 13: 2995-3005.

Excoffier, L., Laval, G., and Schneider, S. 2005. Arlequin ver. 3.0: An integrated software package for population genetics data analysis. Evol. Bioinf. 1:47-50.

Fateh, F. S., Kazmi, M. R., Ahmad, I., and Ashraf, M. 2006. Ceratocystis fimbriata isolated from vascular bundles of declining mango trees in Sindh, Pakistan. Pak. J. Bot. 38:1257-1259.

Felsenstein, J. 1993. PHYLIP (phylogeny inference package) version 3.5c. Distributed by the author. Department of Genetics, University of Washington, Seattle, WA.

Ferreira, E. M., Harrington, T. C., Thorpe, D. J., and Alfenas, A. C. 2010. Genetic diversity and interfertility among highly differentiated populations of Ceratocystis fimbriata in Brazil. Plant Pathol. 59:721-735.

Ferreira, M. A., Harrington, T. C., Alfenas, A. C., and Mitzubuti, E. S. G. 2011. Movement of genotypes of Ceratocystis fimbriata within and among Eucalyptus plantations in Brazil. Phytopathology 101:1005-1012.

Ferreira, M. A., Harrington, T. C., Gongora-Canul, C. C., Mafia, R. G., Zauza, E. A. V., and Alfenas, A. C. 2013. Spatial-temporal patterns of Ceratocystis wilt in Eucalyptus plantations in Brazil. For. Pathol. 43:153-164.

Fourie, A., Wingfield, M. J., Wingfield, B. D., and Barnes, I. 2015. Molecular markers delimit cryptic species in Ceratocystis sensu stricto. Mycol. Progress 11:1020.

Glass, N. L., and Donaldson, G. C. 1995. Development of primer sets designed for use with the PCR to amplify conserved genes from filamentous ascomycetes. Appl. Environ. Microbiol. 61:1323-1330.

Grünwald, N. J., Goodwin, S. B., Milgroom, M. G., and Fry, W. E. 2003. Analysis of genotypic diversity data for populations of microorganisms. Phytopathology 93:738-746.

Harrington, T. C. 2009. The genus Ceratocystis. Where does the oak wilt fungus fit? Pages 21-35 in: Proceedings of the 2nd National Oak Wilt Symposium. D. N. Appel and R. F. Billings, eds. Texas Forest Service Publication 166.

Harrington, T. C. 2013. Ceratocystis diseases. Pages 230-255 in: Infectious Forest Diseases. P. Gonthier and G. Nicolotti, eds. CAB International, Wallingford, UK.

Harrington, T. C., Huang, Q., Ferreira, M. A., and Alfenas, A. C. 2015. Genetic analyses trace the Yunnan, China population of Ceratocystis fimbriata on pomegranate and taro to populations on Eucalyptus in Brazil. Plant Dis. 99:106-111.

Harrington, T. C., Kazmi, M. R., Al-Sadi, A. M., and Ismail, S. I. 2014. Intraspecific and intragenomic variability of ITS rDNA sequences reveals taxonomic problems in Ceratocystis fimbriata sensu stricto. Mycologia 106:224-242.

Harrington, T. C., and McNew, D. L. 1997. Self-fertility and uni-directional mating-type switching in Ceratocystis coerulescens, a filamentous ascomycete. Curr. Genet. 32:52-59.

Harrington, T. C., and McNew, D. L. 1998. Partial interfertility among the Ceratocystis species on conifers. Fungal Genet. Biol. 25:44-53.

Harrington, T. C., and Rizzo, D. M. 1999. Defining species in the fungi. Pages 43-71 in: Structure and Dynamics of Fungal Populations. J. J. Worrall, ed. Kluwer Academic, Dordrecht, the Netherlands.

Harrington, T. C., Thorpe, D. J., and Alfenas, A. C. 2011. Genetic variation and variation in aggressiveness to native and exotic hosts among Brazilian populations of Ceratocystis fimbriata. Phytopathology 101:555-566.

Harrington, T. C., Thorpe, D. J., Marinho, V. L. A., and Furtado, E. L. 2005. First report of black rot of Colocasia esculenta caused by Ceratocystis fimbriata in Brazil. Fitopatol. Bras. 30:88-89.

Johnson, J. A., Harrington, T. C., and Engelbrecht, C. J. B. 2005. Phylogeny and taxonomy of the North American clade of the Ceratocystis fimbriata complex. Mycologia 97:1067-1092.

Katoh, K., and Toh, H. 2010. Parallelization of the MAFFT multiple sequence alignment program. Bioinformatics 26:1899-1900.

Kostermans, A. J. G. H., and Bompard, J. M. 1993. The mangoes: Their botany, nomenclature, horticulture and utilization. IBPGR Academic Press, London, UK.

Masood, A., and Saeed, S. 2012. Bark beetle, Hypocryphalus mangiferae Stebbing (Coleoptera: Curculionidae: Scolytinae) is a vector of mango sudden death disease in Pakistan. Pak. J. Bot. 44:813-820.

Naidoo, K., Steenkamp, E. T., Coetzee, M. P. A., Wingfield, M. J., and Wingfield, B. D. 2013. Concerted evolution in the ribosomal RNA cistron. PLoS One 8:e59355. 
Nkuekam, G. K., Barnes, I., Wingfield, M. J., and Roux, J. 2009. Distribution and population diversity of Ceratocystis pirilliformis in South Africa. Mycologia 101:17-25.

Nylander, J. A. A. 2004. MrModeltest v2. Program distributed by the author. Evolutionary Biology Centre, Uppsala University.

Ocasio-Morales, R. G., Tsopelas, P., and Harrington, T. C. 2007. Origin of Ceratocystis platani on native Platanus orientalis in Greece and its impact on natural forests. Plant Dis. 91:901-904.

Poussio, G. B., Kazmi, M. R., Aken, C., and Fateh, G. S. 2010. First record of Ceratocystis fimbriata associated with shisham (Dalbergia sissoo) decline in Pakistan. Australas. Plant Dis. Notes 5:63-65.

Rayner, R. W. 1970. A Mycological Colour Chart. Commonwealth Mycological Institute and British Mycological Society, Kew, Surrey.

Ronquist, F., and Huelsenbeck, J. P. 2003. MrBayes3: Bayesian phylogenetic inference under mixed models. Bioinformatics 19:1572-1574.

Rossetto, C. J., and Medeiros, J. W. A. 1967. Seca da mangueira. II. Existência do complexo, artrópodos do solo - Ceratocystis fimbriata Scolytidae, no Estado de São Paulo. Rev. Socied. Bras. Fitopatol. 1:19-32.

Rossetto, C. J., and Ribeiro, I. J. A. 1990. Mango wilt. XII. Recommendations for control. Rev. Agric. 65:173-180.

Silveira, S. F., Harrington, T. C., Mussi-Dias, V., Engelbrecht, C. J. B., Alfenas, A. C., and Silva, C. R. 2006. Annona squamosa, a new host of Ceratocystis fimbriata. Fitopatol. Bras. 31:394-97.

Simpson, M. C., Wilken, P. M., Coetzee, M. P. A., Wingfield, M. J., and Wingfield, B. D. 2013. Analysis of microsatellite markers in the genome of the plant pathogen Ceratocystis fimbriata. Fungal Biol. 117:545-555.

Somasekhara, Y. M. 1999. New record of Ceratocystis fimbriata causing wilt of pomegranate in India. Plant Dis. 83:400.

Steimel, J., Engelbrecht, C. J. B., and Harrington, T. C. 2004. Development and characterization of microsatellite markers for the fungus Ceratocystis fimbriata. Mol. Ecol. Notes 4:215-218.

Stoddart, J. A., and Taylor, J. F. 1988. Genotypic diversity: Estimation and prediction in samples. Genetics 118:705-711.

Swofford, D. L. 2002. PAUP 4.0b10: Phylogenetic Analysis Using Parsimony (and other methods). Sinauer Associates, Sunderland, MA

Tamura, K., Peterson, D., Peterson, N., Stecher, G., Nei, M., and Kumar, S. 2011. MEGA5: Molecular evolutionary genetics analysis using maximum likelihood, evolutionary distance, and maximum parsimony methods. Mol. Biol. Evol. 28:2731-2739.
Tarigan, M., Roux, J., van Wyk, M., Tjahjono, B., and Wingfield, M. J. 2011. A new wilt and dieback disease of Acacia mangium associated with Ceratocystis manginecans and C. acaciivora sp. nov. in Indonesia. S. Afr. J. Bot. 77:292-304.

Taylor, J. W., Jacobson, D. J., Kroken, S., Kasuga, T., Geiser, D. M., Hibbett, D. S., and Fischer, M. C. 2000. Phylogenetic species recognition and species concepts in fungi. Fungal Genet. Biol. 31:21-32.

van Wyk, M., Al Adawi, A. O., Khan, I. A., Deadman, M. L., Al Jahwari, A. A., Wingfield, B. D., Ploetz, R., and Wingfield, M. J. 2007. Ceratocystis manginecans sp. nov., causal agent of a destructive mango wilt disease in Oman and Pakistan. Fungal Divers. 27:213-230.

van Wyk, M., Roux, J., Nkuekam, G. K., Wingfield, B. D., and Wingfield, M. J. 2012. Ceratocystis eucalypticola sp. nov. from Eucalyptus in South Africa and comparison to global isolates from this tree. IMA Fungus 3:45-58.

van Wyk, M., van der Merve, N. A., Roux, I., Wingfield, B. D., Kamgan, G. N., and Wingfield, M. J. 2006. Population genetic analyses suggest that the Eucalyptus fungal pathogen Ceratocystis fimbriata has been introduced into South Africa. S. Afr. J. Sci. 102:259-263.

van Wyk, M., Wingfield, B. D., Al-Adawi, A. O., Rossetto, C. J., Ito, M. F., and Wingfield, M. J. 2011a. Two new Ceratocystis species associated with mango disease in Brazil. Mycotaxon 117:381-404.

van Wyk, M., Wingfield, B. D., Marin, M., and Wingfield, M. J. 2010. New Ceratocystis species infecting coffee, cacao, citrus and native trees in Colombia. Fungal Divers. 40:103-117.

van Wyk, M., Wingfield, B. D., Mohali, M., and Wingfield, M. J. 2009. Ceratocystis fimbriatomima, a new species in the $C$. fimbriata sensu lato complex isolated from Eucalyptus trees in Venezuela. Fungal Divers. 34:173-183.

van Wyk, M., Wingfield, B. D., and Wingfield, M. J. 2011b. Four new Ceratocystis spp. associated with wounds on Eucalyptus, Schizolobium and Terminalia trees in Ecuador. Fungal Divers. 46:111-163.

Viégas, A. P. 1960. Seca da mangueira. Bragantia 19:163-182.

Wilken, P. M., Steenkamp, E. T., Wingfield, M. J., de Beer, Z. W., and Wingfield, B. D. 2014. DNA loss at the Ceratocystis fimbriata mating locus results in self-sterility. PLoS One 9:e92180.

Witthuhn, R. C., Harrington, T. C., Wingfield, B. D., Steimel, J., and Wingfield, M. J. 2000. Deletion of the MAT-2 mating-type gene during unidirectional mating-type switching in Ceratocystis. Curr. Genet. 38:48-52.

Yeh, F. C., and Boyle, T. J. 1997. Population genetic analysis of co-dominant and dominant markers and quantitative traits. Belg. J. Bot. 129:157. 